NBER WORKING PAPER SERIES

\title{
THE CASE FOR AUCTIONING COUNTERMEASURES
}

IN THE WTO

Kyle Bagwell

Petros C. Mavroidis

Robert W. Staiger

Working Paper 9920

http://www.nber.org/papers/w9920

\section{NATIONAL BUREAU OF ECONOMIC RESEARCH 1050 Massachusetts Avenue \\ Cambridge, MA 02138}

August 2003

The views expressed herein are those of the authors and not necessarily those of the National Bureau of Economic Research.

(C2003 by Kyle Bagwell, Petros C. Mavroidis, and Robert W. Staiger. All rights reserved. Short sections of text, not to exceed two paragraphs, may be quoted without explicit permission provided that full credit, including (C) notice, is given to the source. 
The Case for Auctioning Countermeasures in the WTO

Kyle Bagwel, Petros C. Mavroidis, and Robert W. Staiger

NBER Working Paper No. 9920

August 2003

JEL No.F1

\section{$\underline{\text { ABSTRACT }}$}

A prominent problem with the WTO dispute settlement procedures is the practical difficulty faced by small and developing countries in finding the capacity to effectively retaliate against trading partners that are in violation of their WTO commitments. In light of this problem, Mexico has proposed that retaliation rights be made "tradeable." We offer a first formal analysis of the possibility that retaliation rights within the WTO system be allocated through auctions. We show that the auctions exhibit externalities among bidders, and we characterize equilibrium bidder behavior under alternative auction formats. A key feature of auction format is whether the country in violation of its WTO commitments is prevented from bidding to retire the right of retaliation: if so, then the possibility of "auction failure" arises, in which no bids are made despite positive valuation by the bidders; if not, then auction failure is precluded, and indeed the right of retaliation is always retired. We also evaluate these different auction formats from normative (revenue, efficiency) standpoints.

Kyle Bagwell

Department of Economics

Columbia University

New York, NY 10027

and NBER

kwb8@columbia.edu

Robert W. Staiger

Department of Economics

University of Wisconsin

1180 Observatory Dirve

Madison, WI 53706

and NBER

rstaiger@facstaff.wisc.edu
Petros C. Mavroidis

Faculty of Lay

University of Neuchatel

106 Faubourg de l'Hopital

CH-2000 Neuchatel

Switzerland

petros.mavroidis@unine.ch 


\title{
The Case for Auctioning Countermeasures in the WTO
}

\author{
Kyle Bagwell, Petros C. Mavroidis, Robert W. Staiger*
}

July 2003

\section{Introduction}

A major accomplishment of the Uruguay Round of GATT negotiations in creating the World Trade Organization (WTO) was the introduction of new dispute settlement procedures. These procedures were intended to provide a significant step forward, relative to GATT, in the settling of trade disputes, in large part by ensuring that violations of WTO commitments would be met with swift retaliation ("suspension of concessions") by the affected trading partners. Yet eight years of experience under the new procedures suggests that significant problems of enforcement remain in the WTO.

One of the more prominent problems with the WTO dispute settlement procedures is the practical difficulty faced by small and developing countries in finding the capacity to effectively retaliate against trading partners that are in violation of their WTO commitments. The difficulty is that, even if a small or developing country wins a ruling against a trading partner under the WTO dispute settlement procedures, and is therefore authorized to retaliate in the event that the trading partner does not bring its policies into conformity with its WTO obligations, the

\footnotetext{
*Bagwell: Columbia University (Kelvin J. Lancaster Professor of Economic Theory in the Department of Economics, and School of Business) and NBER. Staiger: University of Wisconsin at Madison (Department of Economics) and NBER. Mavroidis: Columbia University (Faculty of Law) and University of Neuchatel (Faculty of Law). We thank Isabelle Brocas, Alan Deardorff, Henrick Horn, Giovanni Maggi, Alberto Martin, Kit Rhee, Andres Rodriguez-Clare and seminar participants at the World Bank and the World Trade Forum 2003 for helpful comments. Bagwell and Staiger thank the National Science Foundation (SES-0214021) for financial support.
} 
country may have little ability to bring teeth to the ruling with effective retaliation. As a consequence, many small and developing countries voice frustration with their ability to negotiate meaningful commitments with trading partners in the WTO.

This frustration has been expressed particularly forcefully by Mexico, which has proposed in the WTO (WTO, 2002) a number of changes to the dispute settlement procedures in order to address this problem. Among the changes proposed by Mexico is that the right of retaliation be made "tradeable." The idea is that, if a country wins a ruling against a trading partner under the WTO dispute settlement procedures, and finds that it is unable or unwilling to retaliate itself, it should be able to trade that right to another country that would value and utilize the right of retaliation. In Mexico's view, “...this concept might help address the specific problem facing Members that are unable to suspend concessions effectively." (WTO, 2002, p. 6).

In this paper, we initiate the analytical exploration of tradeable retaliation rights by considering the case for auctioning countermeasures in the WTO. This exploration is novel from the perspective of the theory of trade agreements, where threatened retaliation plays a central role in enforcement, but where auctioning retaliation rights has not been considered. ${ }^{1}$ From the perspective of auction theory, retaliation rights within the WTO exhibit some interesting features as well, because retaliation implies a rich pattern of both positive and negative externalities across trading partners. Recent work in the auction literature has focused on environments with externalities, and the case of auctioning countermeasures in the WTO can be viewed as a novel and interesting environment within which to extend the study of auctions with externalities. ${ }^{2}$

To undertake our analysis, we adopt a simple model in which two foreign countries import a common good from an exporting home country. We assume that each country has bound its tariffs in some previous GATT/WTO negotiation, that the home country has violated its WTO commitments, and that some other (unmodeled) country has been granted a right of retaliation against the home country but is unwilling or unable to exercise this right with a retaliatory tariff of its own. With this country as the "seller," we then consider the implications of

\footnotetext{
${ }^{1}$ See, for example, Bagwell and Staiger (1990, 1997), Dixit (1987), Ederington (2001), Maggi (1999) and Limao (2000). Bagwell and Staiger (2002, Chapter 6) provide a recent review of the existing literature on enforcement of trade agreements.

${ }^{2}$ As discussed below, our formal analysis is most closely related to that of Jehiel and Moldovanu (2000). Other important contributions in this literature include Das Varma (2002), Ettinger (2002), Haile (2000) and Jehiel and Moldovanu (1996, 2001).
} 
allowing the seller to sell the right of retaliation in a first-price sealed-bid auction. We consider two different auction designs. In our basic auction, we allow the two foreign countries to bid for the right to retaliate against the home country, but we do not allow the home country to bid in order to retire this right of retaliation. In our extended auction, we permit the home country to bid as well.

We assume that the two foreign countries experience privately observed politicaleconomy shocks that determine their valuation of the right to impose a higher tariff. In our basic auction, the two foreign countries are the only bidders, and we show that this is an auction with positive externalities: each foreign country would prefer that the other foreign country win the auction and retaliate against the home country over the alternative that no country wins the auction and no retaliation is imposed. Intuitively, the former situation is preferred by each foreign country to the latter situation because of the more favorable foreign terms of trade. We show further that whether a foreign country would in fact prefer to win the right of retaliation over the alternative that the other foreign country wins this right depends on the realization of its privately observed political-economy shock. Intuitively, the more favorable foreign terms of trade will be enjoyed by each foreign country regardless of which foreign country wins the right to retaliate. But the import-competing producers in the winning country enjoy as well the benefits of additional tariff protection at the expense of consumers in that country, and a foreign country that is sufficiently politically motivated - and therefore values the implied redistribution from its consumers to its import-competing producers to a sufficient degree - will prefer to win rather than lose to the other foreign country. Together, as we establish below, these features lead the basic auction to exhibit several unusual properties, including the possibility of misallocation of the retaliation right across the foreign countries and even outright auction failure, in which no bids are made despite positive valuation by the bidders.

When we extend the basic auction to permit the home country to bid to retire the right of retaliation against it, we show that the presence of the home country as a bidder makes the extended auction one with both positive and negative externalities. While each foreign country continues to impose a positive externality on the other foreign country if it wins the auction as compared to the alternative in which no country wins and the retaliation right is retired, each foreign country imposes a negative externality on the home country if it wins. We show that in this extended auction there can be no auction failure, and indeed the home country always wins and retires the retaliation right. Intuitively, the home country incurs the full cost of retaliation, while retaliation is a public good among the foreign 
countries; thus, the home country has the greatest incentive to win the auction. Our analysis of the extended auction also suggests a striking policy implication: when the home country is allowed to bid to retire the right of retaliation, compensation may be achieved without actual tariff retaliation. The simple point is that the home country seeks to avoid a retaliatory foreign tariff, and so it wins the auction and thereby offers cash compensation to the country against whom the violation originally occurred.

We next make normative comparisons across these two auctions on the basis of two criteria. First, in line with the traditional auction literature, we compare the expected revenue across the two auctions, and we further develop the normative motivation for this criterion within the WTO-retaliation-auction context. We find that this first criterion favors the extended auction over the basic auction, as the greatest expected revenue is generated when the home country is permitted to bid to retire the right of retaliation. Second, we compare ex-ante efficiency across the two auctions, where ex-ante efficiency is defined according to the objective functions of the affected governments. We develop the normative motivation for this second criterion as well, and we demonstrate that it can lead to normative conclusions about the wisdom of permitting home to bid that differ from those reached under the expected revenue criterion. A general implication of our analysis is then that the desirability of key auction design features depends critically on what is perceived to be the purpose of introducing auctions in the WTO-retaliation setting.

At a broader level, our analysis suggests that auctioning retaliation rights in the WTO could yield a number of potential indirect benefits for the WTO system. While these indirect benefits are not present in our formal analysis, they include the prospect of greater compliance with WTO obligations that would be raised by providing even small WTO members with the ability to credibly threaten retaliatory action (under the basic auction) or the extraction of compensation (under the extended auction) in the event of WTO violations by their larger trading partners. Also included is the possibility that the prospect of auction revenue might be used by a small developing country to attract and finance private legal support for WTO legal actions that it otherwise could not afford to initiate. Against these additional unmodeled potential benefits would have to be weighed a number of unmodeled potential costs, such as the possibility that the revenue generated by auctions could result in excessive use of the WTO dispute settlement system.

Finally, we note that our formal analysis is closely related to that of Jehiel and 
Moldovanu (2000). They consider second-price sealed-bid auctions with externalities and derive a number of interesting results. Among these, they construct an equilibrium for a general family of payoffs that exhibit positive externalities. In our analysis of the basic auction, we feature an analogous equilibrium. ${ }^{3}$ In this context, the novel aspects of our analysis are: we develop a new trade-policy application, focus on first-price sealed-bid auctions, characterize the necessary properties of equilibrium behavior and thereby establish that the constructed equilibrium is unique, and analyze as well an extended auction wherein bidders are asymmetric and both positive and negative externalities exist.

The rest of the paper proceeds as follows. Section 2 lays out the economic model. The basic auction is defined in Section 3, and the equilibrium bids and revenue are characterized in Section 4. Section 5 defines the extended auction, and Section 6 characterizes the equilibrium bids and revenue in this extended auction. Section 7 compares the two auctions from the perspective of expected revenue and ex-ante efficiency. Section 8 concludes. More technical proofs are contained in the Appendix.

\section{Model}

In this section, we develop the economic framework that underlies our analysis. We present a three-country model, in which two symmetric foreign countries $\left({ }^{*} 1\right.$ and $*_{2}$ ) import a single good from Home. In subsequent sections, we analyze auctions in which the foreign countries bid for the right to retaliate against Home on this good; therefore, we refer to this good as the "retaliation good." Our goal in the present section is to develop an economic model of the retaliation-good sector, define the corresponding welfare functions for governments, and characterize bestresponse, Nash and efficient tariffs.

\footnotetext{
${ }^{3}$ Haile (2000) considers a second-price sealed-bid auction with positive externalities, in which bidders have noisy signals of their private values at the time of the auction and the positive externalities are driven by resale opportunities. In this specific setting, he constructs the unique symmetric equilibrium for a range of binding reserve prices that lie sufficiently below the highest possible valuation. While the particular setting that we analyze is quite different, the equilibrium of our basic auction and that derived by Haile have analogous features, though our results apply to reserve prices up to the highest possible valuation.
} 


\subsection{Economic Model}

The economic model of the retaliation-good sector is simple. For each foreign country $j=1,2$, let demand and supply be given as $D^{*}\left(P^{* j}\right)=1-P^{* j}$ and $Q^{*}\left(P^{* j}\right)=1 / 4$, where $P^{* j}$ is the local price of the retaliation good in foreign country $j$. In the Home country, there is a larger endowment (supply) of this good, but no demand: $D(P)=0$ and $Q(P)=1 / 2$, where $P$ is the local price of the retaliation good in the Home country. It is convenient to define foreign country $j^{\prime} s$ import demand function and Home's export supply function:

$$
\begin{aligned}
M^{*}\left(P^{* j}\right) & =D^{*}\left(P^{* j}\right)-Q^{*}\left(P^{* j}\right)=3 / 4-P^{* j} \\
E(P) & =Q(P)-D(P)=1 / 2
\end{aligned}
$$

Notice that Home exports $1 / 2$ units, regardless of the local price.

Under free trade, we have $P^{* 1}=P^{* 2}=P$, and so global demand and supply equal when $2[1-P]=1$. Thus, the free-trade local price is $P^{* 1}=P^{* 2}=P=1 / 2$. Each foreign country thus imports $1 / 4$ units, with Home exporting $1 / 2$ units.

We now allow that each foreign country imposes an import tariff. Let $\tau^{* j}$ denote foreign country $j$ 's specific tariff. For simplicity, we assume that Home has no export policy. Thus, the world price, $P^{w}$, for the retaliation good must agree with Home's local price: $P=P^{w}$. The local price in foreign country $j$, by contrast, is given as

$$
P^{* j}=P^{w}+\tau^{* j} .
$$

We require as well that the market for the retaliation good clears:

$$
M^{*}\left(P^{* 1}\right)+M^{*}\left(P^{* 2}\right)=E\left(P^{w}\right) .
$$

Using (2.2), we may solve (2.3) for the equilibrium world price, $\widetilde{P}^{w}\left(\tau^{* 1}, \tau^{* 2}\right)$, which is given as

$$
\widetilde{P}^{w}\left(\tau^{* 1}, \tau^{* 2}\right)=\frac{1-\tau^{* 1}-\tau^{* 2}}{2} .
$$

Using (2.2) and (2.4), we find that the equilibrium local price in foreign country $j$, which we denote as $\widehat{P}^{* j}\left(\tau^{* j}, \widetilde{P}^{w}\right)$, is given as

$$
\widehat{P}^{* j}\left(\tau^{* j}, \widetilde{P}^{w}\right) \equiv \widetilde{P}^{w}\left(\tau^{* 1}, \tau^{* 2}\right)+\tau^{* j}=\frac{1-\tau^{* i}+\tau^{* j}}{2},
$$

where $i, j=1,2$ and $i \neq j$. For simplicity, we assume throughout that $\tau^{* j} \leq 1$. 


\subsection{Welfare Functions}

We consider next the welfare functions of the governments of the various countries, with regard to trade in the retaliation-good sector. In line with recent work, we allow that a government is motivated by both national-income and politicaleconomy (i.e., distributional) concerns. ${ }^{4}$

Formally, we represent the welfare function for the government of foreign country $j$ as

$$
W^{* j}\left(\widehat{P}^{* j}, \widetilde{P}^{w}\right)=\int_{\widehat{P}^{* j}}^{1}\left(1-P^{* j}\right) d P^{* j}+\zeta^{* j} \Pi^{*}\left(\widehat{P}^{* j}\right)+\left[\widehat{P}^{* j}-\widetilde{P}^{w}\right] M^{*}\left(\widehat{P}^{* j}\right)
$$

where the first term is consumer surplus, the second term is profit weighted by a political-economy parameter, $\zeta^{* j}$, and the third term is tariff revenue. All of the various functions are defined above, except for foreign country $j$ 's profit, which is defined as

$$
\Pi^{*}\left(P^{* j}\right) \equiv P^{* j}(1 / 4)
$$

As (2.6) reveals, the government of foreign country $j$ experiences a welfare benefit from the world-price reduction (i.e., terms-of-trade improvement) that an increase in any import tariff implies.

With respect to the political-economy parameter, we assume:

A1: For each $j \in\{1,2\}, \zeta^{* j} \in[1,2]$.

Notice that the government of foreign country $j$ maximizes national income when $\zeta^{* j}=1$. Otherwise, the government weighs the profit of import-competing firms above consumer surplus and tariff revenue.

It is convenient to express the welfare function in a simplified manner. Writing welfare as a function of prices, we find that

$$
W^{* j}\left(\widehat{P}^{* j}, \widetilde{P}^{w}\right)=1 / 2+(1 / 4) \widehat{P}^{* j}\left[\zeta^{* j}-1\right]-(1 / 2)\left(\widehat{P}^{* j}\right)^{2}-\widetilde{P}^{w}\left(3 / 4-\widehat{P}^{* j}\right) .
$$

\footnotetext{
${ }^{4}$ For discussion of this literature, see Bagwell and Staiger (1999, 2002 Chapter 2). The formulation that we adopt here is analogous to those used by Bagwell and Staiger (2001) and Baldwin (1987).
} 
Likewise, using (2.4) and (2.5), we find that welfare can be defined as a direct function of tariffs,

$$
\widehat{W}^{* j}\left(\tau^{* j}, \tau^{* i}\right) \equiv W^{* j}\left(\widehat{P}^{* j}\left(\tau^{* j}, \widetilde{P}^{w}\left(\tau^{* 1}, \tau^{* 2}\right)\right), \widetilde{P}^{w}\left(\tau^{* 1}, \tau^{* 2}\right)\right),
$$

and then written as

$$
\widehat{W}^{* j}\left(\tau^{* j}, \tau^{* i}\right)=\frac{\left(1+\zeta^{* j}\right)+\zeta^{* j} \tau^{* j}-3\left(\tau^{* j}\right)^{2}+2 \tau^{* i} \tau^{* j}+\left[2-\zeta^{* j}\right] \tau^{* i}+\left(\tau^{* i}\right)^{2}}{8} .
$$

We consider next the welfare of Home. Letting $\zeta^{H}$ denote the politicaleconomy parameter for Home, we define Home's welfare, $W\left(\widetilde{P}^{w}\right)$, as

$$
W\left(\widetilde{P}^{w}\right)=\zeta^{H}(1 / 2) \widetilde{P}^{w} .
$$

Thus, Home weighs the profit of its export sector, $(1 / 2) \widetilde{P}^{w}$, by a political-economy parameter, $\zeta^{H}$. Observe that Home suffers a welfare loss, when foreign tariffs are increased and the world price declines.

Maintaining symmetry with A1, we make the following assumption:

A2: $\zeta^{H} \in[1,2]$.

This assumption plays no role in the analysis until Sections 5-7.

\subsection{Best-Response and Nash Tariffs}

With the foreign country welfare functions defined, it is now straightforward to characterize non-cooperative tariffs. In particular, we now derive the best-response (optimal) and Nash tariffs.

The best-response function can be found by using (2.8) and setting

$$
W_{\widehat{P}^{* j}}^{* j} \frac{d \widehat{P}^{* j}}{d \tau^{* j}}+W_{\widetilde{P} w}^{* j} \frac{\partial \widetilde{P}^{w}}{\partial \tau^{* j}}=0 .
$$

As this expression reveals, when the government of foreign country $j$ selects its optimal tariff, it considers the impact of the tariff on the local price and the world price. To find the best-response tariff, we may equivalently use (2.9) and set $\frac{\partial \widehat{W}^{* j}}{\partial \tau^{* j}}=0$. We find that the best-response tariff function, $\tau_{R}^{* j}\left(\tau^{* i}\right)$, is given by

$$
\tau_{R}^{* j}\left(\tau^{* i}\right)=\frac{\zeta^{* j}+2 \tau^{* i}}{6}
$$


Notice that the best-response function is upward sloping. This is because the two foreign countries are competing importers: as the tariff of one foreign country rises, more volume is diverted to the other foreign country, and the latter country thus greets the higher volume with a greater tariff as it thereby achieves a large welfare gain from the consequent terms-of-trade improvement. ${ }^{5}$

We next consider foreign country $j$ 's Nash tariff, $\tau_{N}^{* j}$, which is defined by $\tau_{R}^{* j}\left(\tau_{N}^{* i}\right)=\tau_{N}^{* j}$. It is straightforward to derive that

$$
\tau_{N}^{* j}=\frac{3 \zeta^{* j}+\zeta^{* i}}{16}
$$

We observe that $\tau_{N}^{* j}<1 / 2$ under A1. It is interesting to observe further that

$$
\tau_{N}^{* j}-\tau_{N}^{* i}=(1 / 8)\left[\zeta^{* j}-\zeta^{* i}\right] .
$$

The foreign country with the higher political-economy parameter thus sets the higher Nash tariff, as it has greater incentive to raise the local price - and thus the profit of the import-competing sector. Figure 1 illustrates the best-response and Nash tariffs.

\subsection{Efficient Tariffs}

We now characterize efficient tariffs, where efficiency is measured relative to the welfare functions of the three governments. ${ }^{6}$ This characterization clarifies further the central features of our model. In addition, this characterization is useful in Section 7, when we discuss the implications of different auction formats using an efficiency criterion.

A special but convenient feature of our economic model is that Home always exports $1 / 2$ units. Thus, foreign tariffs do not restrict trade in an aggregate sense; rather, tariffs influence the allocation of the fixed volume of Home exports across the foreign countries. This structure is advantageous for two reasons. First, it aligns the model with those used in the auction literature, where a single unit of a good is allocated over bidders. In subsequent sections, we are thus able to build on techniques used in the auction literature. Second, while it is well understood

\footnotetext{
${ }^{5}$ Bagwell and Staiger (1997) examine a related "competing importer" model and likewise find that import tariffs are strategic complements. See also Maggi (1999).

${ }^{6}$ The WTO is an agreement among governments, and we thus analyze the efficiency of this agreement relative to the preferences of governments. For further discussion, see Bagwell and Staiger (1999, 2001, 2002 Chapter 2).
} 
that tariffs may impact efficiency by altering the overall volume of trade, it is less well appreciated that tariffs also may enhance efficiency by allocating a greater share of aggregate trade volume to the importing country whose government most values trade (i.e., to the foreign country whose government weighs least heavily the interests of import-competing firms). This latter role is most easily seen when there is a fixed volume of trade to allocate.

To characterize the efficiency frontier, we begin by deriving the politically optimal tariffs. As discussed by Bagwell and Staiger (1999, 2001, 2002), a government's politically optimal tariff is that tariff which would be optimal, if governments were not motivated by the terms-of-trade implications of their trade policies. In other words, when a government chooses its politically optimal tariff, it achieves its preferred local price. Formally, the politically optimal tariff for foreign country $j$ satisfies $W_{\widehat{P}^{* j}}^{* j}=0$. Using (2.5) and (2.8), we find that the politically optimal tariff, $\tau_{P O}^{* j}$, is given by

$$
\tau_{P O}^{* j}=(1 / 4)\left[\zeta^{* j}-1\right] .
$$

We note that the politically optimal tariff is free trade, when the political-economy parameter is unity (corresponding to national income maximization). We note, too, that under A1 foreign country $j$ 's Nash tariff must exceed its politically optimal tariff: $\tau_{N}^{* j}>\tau_{P O}^{* j}$. This is natural, since foreign country $j$ is motivated by terms-of-trade considerations when setting its Nash tariff.

We turn now to the efficiency frontier. Define joint welfare by

$$
J\left(\tau^{* 1}, \tau^{* 2}\right)=W\left(\widetilde{P}^{w}\right)+W^{* 1}\left(\widehat{P}^{* 1}, \widetilde{P}^{w}\right)+W^{* 2}\left(\widehat{P}^{* 2}, \widetilde{P}^{w}\right) .
$$

When $\zeta^{H}=1$, the world price cancels from this sum, being entirely associated with the redistribution between Home export profit and foreign tariff revenue. ${ }^{7}$ If $\zeta^{H} \neq 1$, then the world price would again cancel from $J$, if Home had its own export policy, since the world price would then be associated with the redistribution of tariff revenue between Home and the foreign countries. But when Home does not have its own export policy, $\widetilde{P}^{w}$ is also associated with Home's local price (i.e., export profit), and so $\widetilde{P}^{w}$ does not cancel from $J$ unless $\zeta^{H}=1$ (so that movements from Home export profit to foreign tariff revenue is entirely redistributive).

For our present purposes, it is sufficient to examine the efficiency frontier when $\zeta^{H}=1$. We then find that

$J\left(\tau^{* 1}, \tau^{* 2}\right)=1+(1 / 4) \widehat{P}^{* 1}\left[\zeta^{* 1}-1\right]-(1 / 2)\left(\widehat{P}^{* 1}\right)^{2}+(1 / 4) \widehat{P}^{* 2}\left[\zeta^{* 2}-1\right]-(1 / 2)\left(\widehat{P}^{* 2}\right)^{2}$.

\footnotetext{
${ }^{7}$ Formally, this conclusion follows from (2.1), (2.3), (2.6) and (2.10).
} 
Setting $\frac{\partial J}{\partial \tau^{* 1}}=0$, we find that efficient tariffs, $\left(\tau_{E}^{* 1}, \tau_{E}^{* 2}\right)$, satisfy

$$
\tau_{E}^{* 1}-\tau_{E}^{* 2}=(1 / 4)\left[\zeta^{* 1}-\zeta^{* 2}\right] .
$$

It may be confirmed that (2.14) also arises when $J$ is maximized with respect to $\tau^{* 2}$. Thus, (2.14) characterizes the set of efficient tariffs when $\zeta^{H}=1$. Notice that the politically optimal tariffs are efficient.

As Figure 2 illustrates, the efficiency frontier is upward sloping. This is, of course, unusual, but it must be remembered that our model is constructed so that tariffs cannot reduce the aggregate volume of trade. Instead, efficiency in our model is all about the allocation of a fixed volume of trade across foreign countries. If foreign country 1 has a higher political-economy parameter than does foreign country 2 (i.e., if $\zeta^{* 1}>\zeta^{* 2}$ ), then it is efficient for foreign country 1 to have a higher local price and thus greater profit in the import-competing sector. This is accomplished by allowing foreign country 1 to select a higher tariff, as (2.14) confirms.

Along the efficiency frontier, the foreign tariff differential is maintained. Of course, at higher tariff pairs along the frontier, the world price is lower, and so movements along the efficiency frontier correspond to redistributions from Home to the foreign countries. But how is the efficient tariff differential determined? At a given world price (i.e., for a given sum of tariffs, $\tau^{* 1}+\tau^{* 2}$ ), efficiency requires that the particular tariffs $\left(\tau^{* 1}\right.$ and $\left.\tau^{* 2}\right)$ maximize the joint welfare of the foreign countries. This amounts to choosing the best local price pair $\left(\widehat{P}^{* 1}, \widehat{P}^{* 2}\right)$, given the fixed world price. This choice involves a tradeoff. First, as discussed above, when political-economy differences are present across foreign countries, the welfare benefit of greater profit in the import-competing sector is larger in the foreign country with the higher political-economy parameter. This force suggests that local prices should vary across foreign countries. Second, the joint consumer surplus and tariff revenue of foreign countries is maximized when local prices are equal across foreign countries. For a given world price, the efficient local price ratio thus represents a balance between the two considerations.

Why isn't the Nash equilibrium efficient? As Figure 2 illustrates, when $\zeta^{* j}>$ $\zeta^{* i}$, the Nash equilibrium entails tariffs for which the tariff differential, $\tau^{* j}-\tau^{* i}$, is smaller than would be efficient. Intuitively, when foreign country $i$ raises its tariff, it does not internalize the fact that a greater share of imports is then diverted to foreign country $j$, whose local price (and thus profit) falls as a result. When $\zeta^{* j}>\zeta^{* i}$, this leads foreign country $i$ to "under-value" the redistributive effect (on profit, across foreign countries) of its tariff increase on foreign country welfare 
for any given world price. By contrast, when $\zeta^{* j}=\zeta^{* i}$, there is no efficiency basis to seek a redistribution of profit from one foreign country to another, and so the Nash equilibrium is efficient.

\section{The Basic Auction: Definition and Payoffs}

In this section, we define and interpret our basic auction. After identifying the different outcomes that may arise in this auction, we characterize and interpret the payoffs that are associated with these outcomes.

\subsection{Definition}

Our basic auction is a first-price sealed-bid auction, where the two foreign coun-

tries are the bidders. Each of the two foreign countries is privately informed of the value of its political-economy parameter, where these parameters, $\zeta^{* 1}$ and $\zeta^{* 2}$, are independently and identically distributed according to a well-behaved (twicecontinuously differentiable) distribution function, $F\left(\zeta^{* j}\right)$, over the support $[1,2]$, with the density function given as $f=F^{\prime}$. After observing $\zeta^{* j}$, foreign country $j$ makes a monetary bid for the right to retaliate. The foreign countries select their bids simultaneously. The bids are selected from the set $\{N\} \cup\left[b_{o}, \infty\right)$, where $N$ corresponds to a decision to "not bid" and $b_{o} \geq 0$ is the reserve price for the auction. A case of particular interest is $b_{o}=0$, in which case the auction has no reserve price. If both countries make a bid (i.e., neither selects $N$ ), then the right of retaliation goes to the high bidder, with each foreign country having an equal chance of gaining the right of retaliation in case of a tie. If one foreign country makes a bid and the other does not, then the right of retaliation goes to the former. Finally, if neither foreign country makes a bid (i.e., both select $N$ ), then the right of retaliation is not assigned, and so no retaliation transpires.

What does retaliation mean? As discussed in the Introduction, we imagine that Home has violated its WTO obligations against some country, but that this country elects not to retaliate on its own. Instead, the harmed country conducts an auction for the right to retaliate against Home. In our basic auction, we assume that two foreign countries bid for the right to retaliate against Home. We now suppose that, through prior negotiations with Home, the two foreign countries have agreed to set their tariffs on the retaliation good at $\tau_{o} \equiv \tau_{o}^{* 1}=\tau_{o}^{* 2} \geq 0$. If a foreign country obtains the right of retaliation, then it is permitted to raise its tariff on the retaliation good to the higher value, $\tau_{o}+\Delta$, where $\Delta>0$. The 
size of $\Delta$ is interpreted as reflecting the size of Home's original violation. ${ }^{8}$ Here, we do not model the nature of Home's original violation, or the selection of the retaliation good, though these are obviously important subjects for discussion and future analysis. Given this focus and the assumed symmetry of the foreign countries, we can regard $\Delta$ as an exogenous number that characterizes the extent of permitted retaliation by the winner (if any) of the auction.

We are interested in the case in which any winner of the auction would, in fact, choose to carry out the retaliation. Intuitively, we may imagine that Home and the foreign countries have negotiated lower tariffs over time, with the status quo being that each now sets its tariff below its reaction curve. Each foreign country would thus enjoy a small tariff hike, if such a hike did not induce a higher Home tariff on some (unmodeled) good that the foreign country exports to Home. ${ }^{9}$ Our focus here is on the auction of retaliation rights, and so we do not put forth a repeated-game model with which to endogenize the status quo tariffs. Using A1, however, we do know that a small retaliation would be carried out if the initial tariffs entail free trade or are politically optimal, for example. More generally, we

\footnotetext{
${ }^{8}$ Under GATT/WTO rules, when it is found that a country has violated its obligations (e.g., by selecting a tariff above the level to which it had agreed), if the offending and harmed countries cannot agree upon "compensation" (e.g., the offending country may offer tariff reductions on other goods that it imports), then the harmed country is authorized to retaliate (e.g., the harmed country may raise its own tariffs), where the level of retaliation is determined as that which restores the original balance of concessions. Working with a general-equilibrium model, Bagwell and Staiger $(1999,2001,2002)$ show that the balance of concessions is restored when the retaliatory action is of a magnitude that restores the offending country's original terms of trade (i.e., the ratio of the price of its export good to its import good on world markets). We consider here the possibility that the harmed country may hold an auction for retaliation of this size. GATT/WTO rules further provide that the retaliation must later be removed if the original violation is later removed, and so more generally we may think of the harmed country as auctioning the per-period rental of the right to retaliate. Finally, we note that the creation of retalitation rights in the GATT/WTO can extend beyond circumstances in which a violation has occurred (e.g., GATT Article XIX, XXIII(b), XXVIII), and our auction model would apply equally well there.

${ }^{9}$ Our model does not provide an efficiency rationale for an agreement between Home and the foreign countries to lower tariffs. First, we do not model the good (or goods) that the foreign countries export to Home. Second, with regard to the good that Home exports, we have assumed that the total export volume is fixed, so that efficiency concerns only the allocation of this volume across foreign countries. As Bagwell and Staiger (1999, 2001, 2002) show, however, in more general settings, efficiency enhancing trade agreements must entail reciprocal tariff reductions. Motivated by this general finding and by the actual nature of trade-policy negotiations, we thus assume that the initial tariffs are below the respective reaction curves, so that each foreign country would carry out a small retaliation.
} 
impose the following assumption:

A3: $\tau_{o} \geq 0, \Delta>0$ and $\tau_{o}+\Delta<1 / 6$.

This assumption implies that $\tau_{o}+\Delta$ is always below each foreign country's reaction curve, since under A1 we have that $1 / 6 \leq \zeta^{* j} / 6=\min _{\tau^{* i}} \tau_{R}^{* j}\left(\tau^{* i}\right)$. Thus, under A1 and A3, when a foreign country wins the right to retaliate, it will exercise this right, regardless of the current realization of its political-economy parameter. ${ }^{10}$

\subsection{Payoffs}

From foreign country $j$ 's perspective, there are three possible outcomes: it may "win" the auction, in which case $\tau^{* j}=\tau_{o}+\Delta$ and $\tau^{* i}=\tau_{o}$; it may "lose" the auction, in which case $\tau^{* j}=\tau_{o}$ and $\tau^{* i}=\tau_{o}+\Delta$; or it may be that "nothing" happens (no country wins the auction), in which case $\tau^{* j}=\tau^{* i}=\tau_{o}$. The respective (gross) payoffs to foreign country $j$ from these three outcomes are:

$$
\begin{aligned}
\omega\left(\zeta^{* j}\right) & \equiv \widehat{W}^{* j}\left(\tau_{o}+\Delta, \tau_{o} ; \zeta^{* j}\right) \\
\lambda\left(\zeta^{* j}\right) & \equiv \widehat{W}^{* j}\left(\tau_{o}, \tau_{o}+\Delta ; \zeta^{* j}\right) \\
\eta\left(\zeta^{* j}\right) & \equiv \widehat{W}^{* j}\left(\tau_{o}, \tau_{o} ; \zeta^{* j}\right),
\end{aligned}
$$

where we now explicitly represent the dependence of welfare on the politicaleconomy parameter.

We now characterize these payoffs. Our first claim is that each foreign country prefers retaliation to nothing, whether that country wins or loses:

Lemma 3.1: $\omega\left(\zeta^{* j}\right)>\eta\left(\zeta^{* j}\right)$ and $\lambda\left(\zeta^{* j}\right)>\eta\left(\zeta^{* j}\right)$.

\footnotetext{
${ }^{10}$ In the context of a larger game in which the status quo tariffs are endogenized, it is natural to associate our model with a later stage that follows the negotiation of the status quo tariffs. After this negotiation is completed, the respective countries may experience political-economy shocks. Such a shock may, for example, motivate Home to violate its agreement. Likewise, the foreign countries receive political-economy shocks that may alter the benefit of a unilateral tariff hike. From this perspective, A3 means that the political-economy parameter for a foreign country would never drop (as compared to its level at the time of the original negotiation) to such an extent that the appeal of a unilateral tariff hike would be lost. This discussion provides some additional context within which to consider our analysis, but we emphasize that such a game would require a separate analysis and is well beyond the reach of the present paper.
} 
Proof: We find that

$$
\begin{aligned}
\omega\left(\zeta^{* j}\right)-\eta\left(\zeta^{* j}\right) & =\widehat{W}^{* j}\left(\tau_{o}+\Delta, \tau_{o} ; \zeta^{* j}\right)-\widehat{W}^{* j}\left(\tau_{o}, \tau_{o} ; \zeta^{* j}\right) \\
& =\frac{\Delta}{8}\left\{\zeta^{* j}-4 \tau_{o}-3 \Delta\right\}>0,
\end{aligned}
$$

where the inequality uses $\mathrm{A} 1\left(\zeta^{* j} \geq 1\right)$ and $\mathrm{A} 3\left(\Delta>0, \tau_{o}+\Delta<1 / 6\right)$.

Likewise, we find that

$$
\begin{aligned}
\lambda\left(\zeta^{* j}\right)-\eta\left(\zeta^{* j}\right) & =\widehat{W}^{* j}\left(\tau_{o}, \tau_{o}+\Delta ; \zeta^{* j}\right)-\widehat{W}^{* j}\left(\tau_{o}, \tau_{o} ; \zeta^{* j}\right) \\
& =\frac{\Delta}{8}\left\{4 \tau_{o}+2-\zeta^{* j}+\Delta\right\}>0,
\end{aligned}
$$

where the inequality uses $\mathrm{A} 1\left(\zeta^{* j} \leq 2\right)$ and $\mathrm{A} 3\left(\tau_{o} \geq 0, \Delta>0\right)$. Q.E.D.

Intuitively, provided that some foreign country wins the auction, retaliation will occur and the resulting reduction in the world price affords a terms-of-trade benefit to both foreign countries. The political-economy parameter cannot be too small (i.e., we use $\zeta^{* j} \geq 1$ ), else the winning country might prefer the lower local price that comes with no retaliation; and the political-economy parameter also cannot be too large (i.e., we use $\zeta^{* j} \leq 2$ ), else the losing country might prefer no retaliation to the low local price that occurs upon losing and thus absorbing diverted trade volume. Under A1, however, there is no ambiguity: the foreign countries agree that someone should retaliate.

But might there be a free-riding problem? This seems plausible if a foreign country would rather lose than win. In this case, retaliation has the aspect of a public good among the foreign countries. Intuitively, whether a foreign country wins or loses, it obtains the benefit of a lower world price. The difference between the two outcomes rests with the local price. If foreign country $j$ wins, then it imposes the retaliatory tariff and obtains a higher local price; whereas, if foreign country $j$ loses, then it absorbs diverted trade volume, and its local price thus drops. Given that the world price is the same in either outcome, the comparison thus boils down to whether foreign country $j$ prefers the higher local price that comes with winning or the lower local price that comes with losing. Now, foreign country $j$ 's preferred local price comes about when its tariff is set at its politically optimal level, $\tau_{P O}^{* j}$. This discussion thus suggests that foreign country $j$ prefers to win rather than lose if $\tau_{o}+\Delta$ is "closer" to $\tau_{P O}^{* j}$ than is $\tau_{o}$.

We now report our formal finding and then return to confirm its relationship to the intuitive discussion just presented: 
Lemma 3.2: Let $\zeta_{c}^{* j} \in(1,2)$ be defined by

$$
\zeta_{c}^{*}=4\left[\tau_{o}+\frac{\Delta}{2}\right]+1 .
$$

Then

$$
\operatorname{sign}\left\{\omega\left(\zeta^{* j}\right)-\lambda\left(\zeta^{* j}\right)\right\}=\operatorname{sign}\left\{\zeta^{* j}-\zeta_{c}^{*}\right\} .
$$

Proof: To establish this result, we use (3.2) and (3.3) and observe that

$$
\begin{aligned}
\omega\left(\zeta^{* j}\right)-\lambda\left(\zeta^{* j}\right) & =\left[\omega\left(\zeta^{* j}\right)-\eta\left(\zeta^{* j}\right)\right]+\left[\eta\left(\zeta^{* j}\right)-\lambda\left(\zeta^{* j}\right)\right] \\
& =\frac{\Delta}{4}\left\{\zeta^{* j}-1-4 \tau_{o}-2 \Delta\right\}
\end{aligned}
$$

so that

$$
\frac{\omega\left(\zeta^{* j}\right)-\lambda\left(\zeta^{* j}\right)}{\Delta}=\frac{\zeta^{* j}-1}{4}-\left(\tau_{o}+\frac{\Delta}{2}\right) .
$$

The lemma now follows by simple rearrangement. Q.E.D.

We now consider further the relationship of this finding to the informal discussion above. Observe that

$$
\begin{aligned}
\tau_{P O}^{* j}-\tau_{o} & =\frac{\zeta^{* j}-1}{4}-\tau_{o} \\
\tau_{o}+\Delta-\tau_{P O}^{* j} & =\tau_{o}+\Delta-\frac{\zeta^{* j}-1}{4}
\end{aligned}
$$

so that $\tau_{o}$ is "closer" to $\tau_{P O}^{* j}$ than is $\tau_{o}+\Delta$ if and only if $\tau_{P O}^{* j}-\tau_{o}<\tau_{o}+\Delta-\tau_{P O}^{* j}$, which is in turn true if and only if $\zeta^{* j}<\zeta_{c}^{*}$. Thus, our informal discussion indicates that when $\zeta^{* j}<\zeta_{c}^{*}$, foreign country $j$ would rather lose (select $\tau_{o}$ ) than win (select $\left.\tau_{o}+\Delta\right)$. But of course this is just what our formal lemma says as well.

We now consider the relationships between the three payoffs in some further detail. Using (2.9) and (3.1), we find the following explicit expressions:

$$
\begin{aligned}
\omega\left(\zeta^{* j}\right) & =\frac{\left(1+\zeta^{* j}\right)+\zeta^{* j}\left(\tau_{o}+\Delta\right)-3\left(\tau_{o}+\Delta\right)^{2}-2 \tau_{o}\left(\tau_{o}+\Delta\right)+\left(2-\zeta^{* j}\right) \tau_{o}+\left(\tau_{o}\right)^{2}}{8} \\
\lambda\left(\zeta^{* j}\right) & =\frac{\left(1+\zeta^{* j}\right)+\zeta^{* j} \tau_{o}-3\left(\tau_{o}\right)^{2}+2 \tau_{o}\left(\tau_{o}+\Delta\right)+\left(2-\zeta^{* j}\right)\left(\tau_{o}+\Delta\right)+\left(\tau_{o}+\Delta\right)^{2}}{8} \\
\eta\left(\zeta^{* j}\right) & =\frac{\left(1+\zeta^{* j}\right)+2 \tau_{o}}{8}
\end{aligned}
$$


Using these explicit payoffs, it is straightforward to confirm the following:

Lemma 3.3: The slopes of $\omega\left(\zeta^{* j}\right), \lambda\left(\zeta^{* j}\right)$ and $\eta\left(\zeta^{* j}\right)$ are positive and satisfy:

$$
\omega^{\prime}\left(\zeta^{* j}\right)=\frac{1+\Delta}{8}>\eta^{\prime}\left(\zeta^{* j}\right)=\frac{1}{8}>\lambda^{\prime}\left(\zeta^{* j}\right)=\frac{1-\Delta}{8} .
$$

This important lemma is illustrated in Figure 3 and captures a simple idea. When the foreign country wins, its local price is higher, and so its importcompeting industry earns greater profit. This is especially valuable when the government places a greater welfare weight on these profits. Thus, $\omega\left(\zeta^{* j}\right)$ increases swiftly with the political-economy parameter. By contrast, when the foreign country loses, the resulting reduction in the local price works to reduce profit in the import-competing industry and is thus particularly painful when the political-economy parameter is large. It follows that $\lambda\left(\zeta^{* j}\right)$ increases slowly with the political-economy parameter. Finally, if no retaliation occurs, then the foreign country's payoff rises with the political-economy parameter at an intermediate speed, corresponding to the direct effect of a higher weight on profit.

Finally, we note that the basic auction is an auction with positive externalities: by Lemma 3.1, any foreign country $j$ prefers that foreign country $i$ win the auction to the situation in which neither foreign country wins the auction (i.e., $\lambda\left(\zeta^{* j}\right)>$ $\left.\eta\left(\zeta^{* j}\right)\right)$. This is because retaliation is a public good among the foreign countries. Both countries benefit from the diminished world price that retaliation implies. As we show in the next section, the presence of a positive externality across bidders has interesting implications for equilibrium bids and revenue.

\section{The Basic Auction: Equilibrium Bids and Revenue}

In this section, we characterize the symmetric (Bayes-Nash) equilibria of the basic auction. Such an equilibrium is described by a bidding function, $b\left(\zeta^{* j}\right)$, that maps from $[1,2]$ into $\{N\} \cup\left[b_{o}, \infty\right)$. We present necessary and sufficient conditions for symmetric equilibria, and we thereby establish the existence of a unique symmetric equilibrium. We also characterize the seller's expected revenue and show that the optimal reserve bid is positive. All omitted proofs are found in the Appendix.

Throughout, we maintain the assumption that $b_{o}$ is sufficiently small, in that it lies below the highest possible valuation for winning versus losing:

A4: $\omega(2)-b_{o}>\lambda(2)$. 
This assumption ensures that the net benefit of winning exceeds that of losing, at least for the highest type. Of course, A4 is satisfied when $b_{o}=0$. We observe further that $\omega(1)-b_{o}>\eta(1)$ is sufficient for $\mathrm{A} 4$. $^{11}$

\subsection{Necessary Conditions}

We begin with the necessary characteristics of a symmetric equilibrium. Our first result establishes the monotonicity of any equilibrium bidding function.

Lemma 4.1: (Monotonicity) In any symmetric equilibrium, if $\zeta_{B}^{* j}>\zeta_{S}^{* j}$ and $b\left(\zeta_{S}^{* j}\right) \neq N$, then (i). $b\left(\zeta_{B}^{* j}\right) \neq N$ and (ii). $b\left(\zeta_{B}^{* j}\right) \geq b\left(\zeta_{S}^{* j}\right)$.

Thus, in any symmetric equilibrium, if a type bids, then any higher type must bid, too, and in fact the higher type chooses a weakly higher bid.

With the monotonicity result at hand, we now report that "auction failure" is a feature of any symmetric equilibrium:

Lemma 4.2: (Auction Failure) In any symmetric equilibrium, $\mathbf{B}<1$, where $\mathbf{B} \equiv$ $\operatorname{prob}\left\{b\left(\zeta^{* j}\right) \neq N\right\}$.

Proof: Fix a symmetric equilibrium. Suppose $\mathbf{B}=1$. Let $\rho\left(\zeta^{* j}\right)$ denote the probability that a foreign firm of type $\zeta^{* j}$ wins the auction with the bid $b\left(\zeta^{* j}\right)$. By Lemma 4.1, the bid function is (weakly) increasing over the support $[1,2]$. Consider a small interval $I$ of types just above 1 . For any $\zeta^{* j} \in I, \rho\left(\zeta^{* j}\right)>0$. Thus, for any $\zeta^{* j} \in I$, a strict gain could be achieved by deviating to $N$, since

$$
\lambda\left(\zeta^{* j}\right)>\rho\left(\zeta^{* j}\right)\left[\omega\left(\zeta^{* j}\right)-b\left(\zeta^{* j}\right)\right]+\left(1-\rho\left(\zeta^{* j}\right)\right) \lambda\left(\zeta^{* j}\right)
$$

follows from $\rho\left(\zeta^{* j}\right)>0, \lambda(1)>\omega(1)$, and $b\left(\zeta^{* j}\right) \geq b_{o} \geq 0$. This contradicts $\mathbf{B}=1$. Q.E.D.

This lemma holds even when $b_{o}=0$. Intuitively, if all types were to bid, then the lower types would do better yet by not bidding, since they could then be sure to lose whereas bidding runs a small risk of winning.

Our monotonicity and auction-failure findings imply a simple characterization of the types that do not bid:

\footnotetext{
${ }^{11}$ If $\omega(1)-b_{o}>\eta(1)$, then using (3.5) and (3.2) we have $\omega(2)-\lambda(2)-b_{o}>(\omega(2)-\lambda(2))-$ $(\omega(1)-\eta(1))=\frac{\Delta}{2}\left\{\frac{1}{4}-\tau_{o}-\frac{\Delta}{4}\right\}>0$.
} 
Lemma 4.3: In any symmetric equilibrium, there exists $\zeta_{L}^{*} \in(1,2)$ such that $b\left(\zeta^{* j}\right)=N$ for all $\zeta^{* j}<\zeta_{L}^{*}$, and $b\left(\zeta^{* j}\right) \neq N$ for all $\zeta^{* j}>\zeta_{L}^{*}$.

Proof: By Lemma 4.2, we know that a positive measure of types do not bid. Using Lemma 4.1, we know further that the set of such types must take the form $\left[1, \zeta_{L}^{*}\right)$, since once active bidding begins it continues for all higher types. Thus, $\zeta_{L}^{*}>1$. Now suppose that $\zeta_{L}^{*}=2$, so that no types bid $(\mathbf{B}=0)$. In this case, using A4, a foreign country with type near $\zeta^{* j}=2$ would strictly gain by deviating and bidding $b_{o}$, since $\omega(2)-b_{o}>\lambda(2)>\eta(2)$. Q.E.D.

We consider now features of the equilibrium bidding function for $\zeta^{* j}>\zeta_{L}^{*}$. We find that a region of pooling must exist:

Lemma 4.4: In any symmetric equilibrium, there exists $\zeta_{H}^{*} \in\left(\zeta_{L}^{*}, 2\right)$ such that $b\left(\zeta^{* j}\right)=b_{o}$ for all $\zeta^{* j} \in\left(\zeta_{L}^{*}, \zeta_{H}^{*}\right)$ and $b\left(\zeta^{* j}\right)>b_{o}$ for $\zeta^{* j}>\zeta_{H}^{*}$.

Together with Lemma 4.3, this lemma indicates that lower types refrain from bidding, intermediate types pool at the reserve bid, and higher types bid above the reserve bid.

It is instructive here to sketch the proof. First, we show that it is not possible for an interval of types to pool at some value $\widetilde{b}>b_{o}$. If such a pooling bid were posited, then all types on that interval could not be indifferent between winning (with the bid $\widetilde{b}$ ) and losing; thus, it would be necessary that some type exists that prefers to deviate to a slightly higher bid (thus winning more often) or to a slightly lower bid (thus losing more often). By contrast, pooling at $b_{o}$ is possible, since a slightly lower bid is then not possible. Second, we show that an interval of types, beginning at $\zeta_{L}^{*}$, must pool at the bid $b_{o}$. Intuitively, if $b$ were strictly increasing over $\left(\zeta_{L}^{*}, 2\right]$, then it would be necessary that type $\zeta_{L}^{*}$ is indifferent between bidding $b_{o}$ and not bidding: $\omega\left(\zeta_{L}^{*}\right)-b_{o}=\eta\left(\zeta_{L}^{*}\right)$. But this implies that $\omega\left(\zeta_{L}^{*}\right)-b_{o}<\lambda\left(\zeta_{L}^{*}\right)$, and so types just above $\zeta_{L}^{*}$ would gain from deviating to a lower bid (such as $b_{o}$ ), since they then benefit by losing more often (and pay less when winning). Third, we show that the highest types are unwilling to pool at $b_{o}$, since under A4 such types would gain from deviating to a higher bid and winning more often.

We consider next the behavior of the bidding function for higher types, described by $\zeta^{* j} \geq \zeta_{H}^{*}$. We find a region over which the bidding function is continuous and strictly increasing:

Lemma 4.5: In any symmetric equilibrium, $b\left(\zeta_{H}^{*}\right)=b_{o}, b\left(\zeta^{* j}\right)$ is continuous over $\zeta^{* j} \in\left[\zeta_{H}^{*}, 2\right]$, and $b\left(\zeta^{* j}\right)$ is strictly increasing over $\zeta^{* j} \in\left(\zeta_{H}^{*}, 2\right]$. 
Intuitively, higher types prefer winning to losing, and so such types bid aggressively. Over this range, the equilibrium bidding function is thus strictly increasing, just as it is in a standard first-price auction without externalities.

At this point, we have characterized the qualitative properties that the bidding function must take in any symmetric equilibrium. Our next task is to characterize the critical values, $\zeta_{L}^{*}$ and $\zeta_{H}^{*}$. To this end, we proceed in two steps. First, we define and characterize two key values for $\zeta^{* j}$. Second, we show that these key values correspond to $\zeta_{L}^{*}$ and $\zeta_{H}^{*}$.

The two key values are denoted as $\bar{\zeta}^{*}\left(b_{o}\right)$ and $\widetilde{\zeta}^{*}\left(b_{o}\right)$. The value $\widetilde{\zeta}^{*}\left(b_{o}\right)$ is defined as the solution to the following equation:

$$
\omega\left(\zeta^{* j}\right)-\lambda\left(\zeta^{* j}\right)=b_{o} .
$$

This value is characterized as follows:

Lemma 4.6: $\bar{\zeta}^{*}\left(b_{o}\right)$ takes the following form:

$$
\bar{\zeta}^{*}\left(b_{o}\right)=1+4 \tau_{o}+2 \Delta+\frac{4}{\Delta} b_{o} \in(1,2) .
$$

Given the definition of $\bar{\zeta}^{*}=\bar{\zeta}^{*}\left(b_{o}\right)$ in $(4.2)$, we define $\widetilde{\zeta}^{*}\left(b_{o}\right)$ as the solution to the following equation:

$$
\left(F\left(\bar{\zeta}^{*}\right)-F\left(\zeta^{* j}\right)\right)\left[\frac{\lambda\left(\zeta^{* j}\right)-\left(\omega\left(\zeta^{* j}\right)-b_{o}\right)}{2}\right]=F\left(\zeta^{* j}\right)\left[\omega\left(\zeta^{* j}\right)-b_{o}-\eta\left(\zeta^{* j}\right)\right] .
$$

We characterize this value as follows:

Lemma 4.7: $\widetilde{\zeta}^{*}\left(b_{o}\right)$ is uniquely defined, $\widetilde{\zeta}^{*}\left(b_{o}\right) \in\left(1, \widetilde{\zeta}^{*}\left(b_{o}\right)\right)$ and $\frac{d \widetilde{\zeta}^{*}}{d b_{o}}>0$.

We proceed now to our second step and establish a relationship between the key values, $\widetilde{\zeta}^{*}\left(b_{o}\right)$ and $\widetilde{\zeta}^{*}\left(b_{o}\right)$, and the necessary features of a symmetric equilibrium.

Lemma 4.8: In any symmetric equilibrium, $\zeta_{H}^{*}=\bar{\zeta}^{*}\left(b_{o}\right)$ and $\zeta_{L}^{*}=\widetilde{\zeta}^{*}\left(b_{o}\right)$.

To complete our characterization of the necessary features of a symmetric equilibrium, we now derive the form that the bidding function takes over $\zeta^{* j} \in$ $\left[\zeta_{H}^{*}, 2\right]$. To this end, we fix $\zeta^{* j}$ and consider $\widehat{\zeta}^{* j} \in\left[\zeta_{H}^{*}, 2\right]$. Suppose that foreign 
country $j$ has type $\zeta^{* j}$ and bids as if its type were $\widehat{\zeta}^{* j}$. Given that the rival country uses the equilibrium bidding function, the payoff to foreign country $j$ is then

$$
U\left(\widehat{\zeta}^{* j}, \zeta^{* j}\right) \equiv F\left(\widehat{\zeta}^{* j}\right)\left[\omega\left(\zeta^{* j}\right)-b\left(\widehat{\zeta}^{* j}\right)\right]+\left[1-F\left(\widehat{\zeta}^{* j}\right)\right] \lambda\left(\zeta^{* j}\right) .
$$

With the monotonicity of $b$ embedded, we observe this function satisfies the singlecrossing condition:

$$
U_{12}\left(\widehat{\zeta}^{* j}, \zeta^{* j}\right)=F^{\prime}\left(\widehat{\zeta}^{* j}\right)\left[\omega^{\prime}\left(\zeta^{* j}\right)-\lambda^{\prime}\left(\zeta^{* j}\right)\right]>0 .
$$

For our present purposes, the important point is that a symmetric equilibrium exists only if the local incentive constraint is satisfied: for all $\zeta^{* j} \in\left[\zeta_{H}^{*}, 2\right]$,

$$
U_{1}\left(\widehat{\zeta}^{* j}, \zeta^{* j}\right)=0 \text { when } \widehat{\zeta}^{* j}=\zeta^{* j}
$$

Recalling from Lemma 4.8 that $\zeta_{H}^{*}=\bar{\zeta}^{*}$, it is now possible to use (4.6) to characterize the necessary features of the bidding function for $\zeta^{* j} \in\left[\bar{\zeta}^{*}, 2\right]$.

Lemma 4.9: In any symmetric equilibrium, when foreign country $j$ has type $\zeta^{* j} \in\left[\bar{\zeta}^{*}, 2\right]$, it bids

$$
b\left(\zeta^{* j}\right)=\omega\left(\zeta^{* j}\right)-\lambda\left(\zeta^{* j}\right)-\frac{\Delta}{4} \frac{1}{F\left(\zeta^{* j}\right)} \int_{\bar{\zeta}^{*}}^{\zeta^{* j}} F(x) d x .
$$

and expects to pay

$$
F\left(\zeta^{* j}\right) b\left(\zeta^{* j}\right)=F\left(\zeta^{* j}\right)\left[\omega\left(\zeta^{* j}\right)-\lambda\left(\zeta^{* j}\right)\right]-\frac{\Delta}{4} \int_{\bar{\zeta}^{*}}^{\zeta^{* j}} F(x) d x
$$

Intuitively, this lemma has the familiar interpretation that a bidder in a first-price auction "shades" the bid relative to the true valuation, once it is understood that the bidder's valuation over the range of focus corresponds to the value of winning relative to losing, $\omega\left(\zeta^{* j}\right)-\lambda\left(\zeta^{* j}\right)$.

We may now summarize the various findings above into a single proposition that states the necessary implications of a symmetric equilibrium:

Proposition 4.1: In any symmetric equilibrium, 
(i). for all $\zeta^{* j} \in\left[1, \widetilde{\zeta}^{*}\right), b\left(\zeta^{* j}\right)=N$,

(ii). for all $\zeta^{* j} \in\left(\widetilde{\zeta}^{*}, \bar{\zeta}^{*}\right], b\left(\zeta^{* j}\right)=b_{o}$, and

(iii). for all $\zeta^{* j} \in\left(\bar{\zeta}^{*}, 2\right], b\left(\zeta^{* j}\right)$ is strictly increasing and given as

$$
b\left(\zeta^{* j}\right)=\omega\left(\zeta^{* j}\right)-\lambda\left(\zeta^{* j}\right)-\frac{\Delta}{4} \frac{1}{F\left(\zeta^{* j}\right)} \int_{\bar{\zeta}^{*}}^{\zeta^{* j}} F(x) d x
$$

The values $\widetilde{\zeta}^{*}$ and $\bar{\zeta}^{*}$ depend upon $b_{o}$ and are defined by (4.3) and (4.1). They satisfy $\bar{\zeta}^{*} \in(1,2)$ and $\widetilde{\zeta}^{*} \in\left(1, \bar{\zeta}^{*}\right)$.

Figure 4 illustrates the bidding function.

\subsection{Sufficient Conditions}

With the necessary features now established, we turn last to sufficiency. In particular, we confirm that the stated bidding function does indeed constitute a symmetric equilibrium.

Proposition 4.2: The bidding function defined in Proposition 4.1 constitutes a symmetric equilibrium.

The proof relies on the constructed indifference of types $\widetilde{\zeta}^{*}$ and $\bar{\zeta}^{*}$, along with the single-crossing property of $U$ as captured in (4.5).

Together, Propositions 4.1 and 4.2 indicate that we have now characterized the unique symmetric equilibrium for our basic auction. Summarizing:

Corollary 4.1: For the basic auction, there exists a unique symmetric equilibrium. In this equilibrium, the governments of the foreign countries use the bidding function defined in Proposition 4.1.

In auctions without externalities, the first-price auction is allocatively efficient: the bidding function is strictly increasing, and so the highest-valuation bidder always obtains the item. In the setting considered here, however, positive externalities exist. We find that a first-price auction then no longer ensures that retaliation is efficiently allocated: auction failure may result, so that no bidder wins the right to retaliate; and even when bidding occurs, it may be that both foreign countries bid at the reserve price and the right of retaliation is misallocated. 
On the other hand, when at least one foreign country has a high political-economy parameter, then bidding is more aggressive and the auction allocates retaliation across the foreign countries in an efficient manner.

\subsection{Optimal Auctions}

We now briefly consider the revenue-maximizing reserve bid for the seller. We assume that the seller places no value on the right of retaliation and thus seeks only to maximize expected revenue. ${ }^{12}$

We begin with a characterization of the seller's expected revenue:

Lemma 4.10: In the symmetric equilibrium, the seller's expected revenue is

$2 P\left(b_{o}\right)=b_{o}\left[F^{2}\left(\bar{\zeta}^{*}\right)-F^{2}\left(\widetilde{\zeta}^{*}\right)\right]+2 \int_{\bar{\zeta}^{*}}^{2} F\left(\zeta^{* j}\right)\left\{\left[\omega\left(\zeta^{* j}\right)-\lambda\left(\zeta^{* j}\right)\right] F^{\prime}\left(\zeta^{* j}\right)-\frac{\Delta}{4}\left(1-F\left(\zeta^{* j}\right)\right)\right\} d \zeta^{* j}$

With the expected revenue of the seller now characterized, we next analyze the seller's optimal reserve price. We find:

Proposition 4.3: When the seller sets the reserve bid to maximize expected revenue, the optimal reserve bid is positive.

This proposition establishes that the seller sets the reserve bid above the seller's own valuation for the item, which in the present setting is taken to be zero. When the reserve bid is raised above zero, the possibility of auction failure increases (recall that $\widetilde{\zeta}^{*}\left(b_{o}\right)$ is strictly increasing), but expected revenue rises since the expected bid is then higher.

\footnotetext{
${ }^{12}$ If the seller has a positive valuation for the right of retaliation, then the natural interpretation is that the seller would impose retaliation on some export of Home in the event of auction failure. This possibility might in turn affect the payoffs to the foreign countries when auction failure occurs, as they might benefit from the seller's retaliation effort. A full analysis of this issue requires a larger model, in which the seller's trading relationships are more fully treated. We leave this to future work.
} 


\section{The Extended Auction: Definition and Payoffs}

In this section, we define and interpret an extended auction, in which the foreign countries and Home are all bidders. We then define and characterize Home's payoffs for the extended auction.

\subsection{Definition}

We now consider an extended auction, in which Home can bid to retire the right of retaliation. In particular, Home places a bid at the same time that the foreign countries make their respective bids, where the space of possible bids for each country is $\{N\} \cup\left[b_{o}, \infty\right)$. If no country bids at or above $b_{o}$, then no retaliation occurs and no auction revenue is received. If some country does bid $b_{o}$ or more, then the highest bidder wins the auction. In the event of a tie, the auction treats foreign countries symmetrically, but we will allow that Home may be treated differently than the foreign countries. For example, Home may win all ties. ${ }^{13}$ In the event that Home wins, the right of retaliation is retired, and Home transfers its bid to the seller. By contrast, if a foreign country wins the auction, then, as in the basic auction, the winning foreign country retaliates and transfers its bid to the seller. To keep our analysis tractable, we assume that Home's politicaleconomy type is publicly known and constant at some value $\zeta^{H} \in[1,2]$. As in the basic auction, the foreign countries' respective types are privately known.

\subsection{Payoffs}

The payoffs to the foreign countries are defined as in the basic auction. We focus here on Home's payoff under the different outcomes (retaliation, no retaliation) that may arise in the extended auction.

In the event that Home does not face retaliation (whether because both foreign countries select $N$ or Home bids more), we may use (2.4) to derive that the equilibrium world price is

$$
\widetilde{P}_{N R}^{w} \equiv \widetilde{P}^{w}\left(\tau_{o}, \tau_{o}\right)=\frac{1}{2}-\tau_{o}
$$

\footnotetext{
${ }^{13}$ Our results hold as well under the requirement that Home and foreign countries are treated symmetrically when ties occur. By allowing that Home is treated differently in ties, we are able to state a simple specification for equilibrium strategies.
} 
Likewise, if Home does face retaliation, then the equilibrium world price is

$$
\widetilde{P}_{R}^{w} \equiv \widetilde{P}^{w}\left(\tau_{o}+\Delta, \tau_{o}\right)=\frac{1}{2}-\tau_{o}-\frac{\Delta}{2} .
$$

Now recall from (2.10) that Home's welfare is given as $W\left(\widetilde{P}^{w}\right)=\zeta^{H}(1 / 2) \widetilde{P}^{w}$, where $\zeta^{H} \in[1,2]$ under A2. Thus, Home's (gross) payoff under no retaliation and retaliation is given as

$$
\begin{gathered}
W_{N R} \equiv \zeta^{H}(1 / 2) \widetilde{P}_{N R}^{w}=\zeta^{H}(1 / 2)\left(\frac{1}{2}-\tau_{o}\right) . \\
W_{R} \equiv \zeta^{H}(1 / 2) \widetilde{P}_{R}^{w}=\zeta^{H}(1 / 2)\left(\frac{1}{2}-\tau_{o}-\frac{\Delta}{2} .\right) .
\end{gathered}
$$

Using (5.1) and (5.2), we may thus define Home's "valuation" of no retaliation as

$$
W_{N R}-W_{R}=\zeta^{H} \frac{\Delta}{4} .
$$

We now recall A4, which ensures that the reserve bid is small relative to the value that a foreign country of the highest type places on winning versus losing. We now show that A4 also has implications for Home's willingness to bid:

Lemma 5.1: For any $\zeta^{H} \geq 1$,

$$
W_{N R}-W_{R}>\omega(2)-\eta(2)>\omega(2)-\lambda(2)>b_{o} .
$$

Proof: Using (5.3), we find that

$$
\begin{aligned}
W_{N R}-W_{R} & =\zeta^{H} \frac{\Delta}{4} \geq \frac{\Delta}{4}>\frac{\Delta}{4}-\frac{\Delta}{8}\left[4 \tau_{o}+3 \Delta\right] \\
& =\omega(2)-\eta(2)>\omega(2)-\lambda(2)>b_{o},
\end{aligned}
$$

where the first inequality uses A2 $\left(\zeta^{H} \geq 1\right)$, the second inequality uses $\mathrm{A} 3$, the subsequent equality uses (3.2), the next inequality uses (3.3), and the final inequality uses A4. Q.E.D.

As we will show, this lemma ensures that Home has the greatest incentive to win the auction. Intuitively, Home receives all of the cost of a reduction in the world price, while each foreign country enjoys only a share of the benefit. 
A novel feature of our extended auction is that both positive and negative externalities are present. As in the basic auction, a positive externality arises across foreign countries: each foreign country prefers that the other foreign country win to the possibility that neither foreign country wins (i.e., $\lambda\left(\zeta^{* j}\right)>\eta\left(\zeta^{* j}\right)$ ). In the extended auction, however, Home is also a bidder, and a negative externality arises between Home and the foreign countries: Home prefers that no country win to the possibility that a foreign country wins, since retaliation is avoided only in the former case (i.e., $W_{N R}>W_{R}$ ).

\section{The Extended Auction: Equilibrium Bids and Revenue}

We again look for symmetric equilibria, where symmetry in the extended auction means that foreign countries adopt symmetric strategies. Home may adopt an asymmetric strategy, and recall, too, that the extended auction may treat Home differently than the foreign countries, in the event that Home ties with one or both foreign countries. As above, we focus on pure-strategy equilibria. Let $b_{H} \in$ $\{N\} \cup\left[b_{o}, \infty\right)$ denote Home's bid.

Our first step is to determine whether a symmetric equilibrium exists in which Home always loses (i.e., a foreign country wins the right of retaliation with probability one). Our result is as follows:

Lemma 6.1: In any symmetric equilibrium of the extended auction, if $b_{o}$ is sufficiently close to zero, then $b_{H} \neq N$ and Home cannot always lose.

Proof: To begin, we assume to the contrary that $b_{H}=N$. The foreign firms then bid as characterized above for the basic auction. Home's payoff from $b_{H}=N$ is thus $F^{2}\left(\widetilde{\zeta}^{*}\right) W_{N R}+\left[1-F^{2}\left(\widetilde{\zeta}^{*}\right)\right] W_{R}$. Notice that Home sometimes enjoys the noretaliation outcome, due to auction failure among the foreign countries. If Home were to deviate and bid $b_{o}+\epsilon$, for $\epsilon>0$ and small, then Home's payoff would be $F^{2}\left(\bar{\zeta}^{*}\right)\left[W_{N R}-b_{o}\right]+\left[1-F^{2}\left(\bar{\zeta}^{*}\right)\right] W_{R}$, approximately. Thus, using (5.3), Home does better by deviating if and only if

$$
\left[1-\frac{F^{2}\left(\widetilde{\zeta}^{*}\right)}{F^{2}\left(\bar{\zeta}^{*}\right)}\right]\left[\zeta^{H} \frac{\Delta}{4}\right]>b_{o} .
$$

Since $\bar{\zeta}^{*}>\widetilde{\zeta}^{*}$ and $\zeta^{H} \frac{\Delta}{4}>b_{o}$ (by (5.4)), this inequality is sure to hold when $b_{o}$ is sufficiently close to zero. 
Next, we suppose that $b_{H} \neq N$ and yet Home always loses. This is possible only if $b_{H} \geq b_{o}$ and $b\left(\zeta^{* j}\right) \geq b_{H}$ for all $\zeta^{* j} \in[1,2]$. In that event, though, a foreign firm with type close to 1 wins with positive probability and would do better by deviating to $N$. The other foreign country would then win with probability one, and so the deviating foreign country would enjoy the payoff $\lambda\left(\zeta^{* j}\right)$, which exceeds the value of the weighted sum of $\omega\left(\zeta^{* j}\right)-b\left(\zeta^{* j}\right)$ and $\lambda\left(\zeta^{* j}\right)$ that it receives in the putative equilibrium. For further details, see the proof of Lemma 4.2, where an analogous argument is made. Q.E.D.

It is tempting to conjecture that this lemma holds for any $b_{o}$. One might argue that, if a foreign country is willing to bid, then surely Home would be willing to bid more. After all, as Lemma 5.1 establishes, Home gets more from stopping retaliation than any foreign country gains from having retaliation occur (whether as a winner or a loser). This argument, however, is incomplete, as it ignores the fact that Home may enjoy no retaliation even when not bidding. This happens when the foreign countries get stuck in an auction failure. Thus, it is not obvious that Home would always outbid the highest type of foreign country. We show in the lemma, however, that Home will certainly do so if $b_{o}$ is sufficiently small.

Our second step is to consider whether symmetric equilibria exist in which Home always wins (i.e., a foreign country wins the right to retaliate with probability zero). In fact, it is simple to construct equilibria of this kind.

Lemma 6.2: There exist symmetric equilibria of the extended auction in which Home always wins. One set of such equilibria is specified as follows:

$$
\begin{aligned}
b_{H} \in & {\left[\omega(2)-\eta(2), \zeta^{H} \frac{\Delta}{4}\right] } \\
b\left(\zeta^{* j}\right)= & b_{H}, \text { for all } \zeta^{* j} \in[1,2] \\
& \text { Home wins all ties. }
\end{aligned}
$$

Furthermore, in any equilibrium in which Home always wins, $b_{H} \in[\omega(2)-$ $\left.\eta(2), \zeta^{H} \frac{\Delta}{4}\right]$.

Proof: We begin by establishing existence. Consider Home. A higher bid is clearly not an attractive deviation. A lower bid is also an unattractive deviation. Such a bid ensures certain retaliation, which implies a loss for Home since

$$
W_{N R}-b_{H} \geq W_{N R}-\zeta^{H} \frac{\Delta}{4}=W_{R} .
$$


Consider next a foreign country. Of course, such a country is unable to gain from a lower bid, since then it would only continue to lose. A higher bid would be most attractive to a foreign country of type $\zeta^{* j}=2$. But if this type were to bid $b_{H}+\epsilon$, for $\epsilon>0$ and small, then its payoff would be

$$
\omega(2)-\left(b_{H}+\epsilon\right)<\omega(2)-b_{H} \leq \omega(2)-[\omega(2)-\eta(2)]=\eta(2),
$$

and so the deviation is less attractive than bidding $b_{H}$ and losing to Home. Thus, the strategies specified in (6.1) constitute a symmetric equilibrium for the extended auction.

Next, we establish that any such equilibrium must have $b_{H} \in\left[\omega(2)-\eta(2), \zeta^{H} \frac{\Delta}{4}\right]$. Suppose Home always wins and $b_{H}<\omega(2)-\eta(2)$. Then when a foreign country has a type near 2, it would gain by deviating to $b_{H}+\epsilon$, for $\epsilon$ positive and small, as it thereby receives approximately $\omega(2)-b_{H}>\eta(2)$. Suppose next that Home always wins and $b_{H}>\zeta^{H} \frac{\Delta}{4}$. Then $W_{N R}-b_{H}<W_{N R}-\zeta^{H} \frac{\Delta}{4}=W_{R}$, and so Home would gain by deviating and selecting $N$, as it then either enjoys $W_{N R}$ (in the event of auction failure) or $W_{R}$. Q.E.D.

A potential objection to the specification in Lemma 6.2 is that the foreign countries use dominated strategies. In particular, for a foreign country of type $\zeta^{* j}$, any bid $b$ such that $b>\max \left\{\omega\left(\zeta^{* j}\right)-\eta\left(\zeta^{* j}\right), b_{o}\right\}$ is dominated by the alternative strategy of selecting $N .{ }^{14}$ It follows that the specification used in (6.1) involves the use of a dominated strategy by all types of foreign country other than the type $\zeta^{* j}=2$.

This objection suggests that it is important to determine whether an equilibrium can be established without the use of dominated strategies. In the auction game considered here, Home will resist cutting its bid from $b_{H}$ provided that enough foreign types bid at or near $b_{H}$. Intuitively, when $b_{H}<\zeta^{H} \frac{\Delta}{4}$, a lower bid generates a higher Home payoff when Home wins, but reduces Home's payoff when Home loses. Thus, if Home perceives a sufficient probability of losing when it shades its bid, then Home will refrain from shading. For this to be true, it is not necessary that the foreign country types all bid $b_{H}$. It is necessary only that

\footnotetext{
${ }^{14}$ To see this, note that the selection of $N$ yields payoff $\eta\left(\zeta^{* j}\right)$ or $\lambda\left(\zeta^{* j}\right)$, depending upon whether the other foreign country wins. By contrast, the bid of $b$ yields payoff $\omega\left(\zeta^{* j}\right)-b<$ $\eta\left(\zeta^{* j}\right)<\lambda\left(\zeta^{* j}\right)$ when $b$ is the winning bid, yields the payoff $\lambda\left(\zeta^{* j}\right)$ when the other foreign country wins, and yields the payoff $\eta\left(\zeta^{* j}\right)$ otherwise. Thus, the strategy of selecting $N$ yields a greater payoff than the strategy of selecting $b$ whenever $b$ would be the winning bid, and the strategy of selecting $N$ yields the same payoff as the strategy of selecting $b$ whenever $b$ would not be the winning bid.
} 
the probability is sufficiently high that a foreign country bid will fall at or just below $b_{H}$.

As the following lemma establishes, however, it is not always possible to construct a symmetric equilibrium in which Home always wins while insisting the foreign countries do not use dominated strategies:

Lemma 6.3: In the extended auction, if the foreign countries do not use dominated strategies and $F^{\prime}(2)<3 / 16$, then there does not exist a symmetric equilibrium in which Home always wins.

The proof is in the Appendix. Intuitively, it is impossible to stop Home from cutting its bid from $b_{H}=\omega(2)-\eta(2)$, if it is unlikely that a foreign country bids at or just below $b_{H}$. In turn, if there aren't too many foreign country types that are high (i.e., if $F^{\prime}(2)$ is small) and if foreign countries do not use dominated strategies, then it is unlikely that a foreign country bids at or just below $b_{H}$.

As Lemma 6.3 indicates, the requirement that dominated strategies not be used can have important existence implications. If the density is low over the region of highest foreign types, then this requirement can preclude the existence of symmetric equilibria in which Home always wins. ${ }^{15}$ We show above that, when $b_{o}$ is small, symmetric equilibria do not exist in which Home always loses, and we establish just below that symmetric equilibria also fail to exist in which Home sometimes wins (i.e., a foreign country wins the right to retaliate with probability between zero and one). If a symmetric equilibrium exists when $b_{o}$ is small, then it must involve Home always winning. Existence of a symmetric equilibrium is thus not assured unless we allow that dominated strategies may be used. ${ }^{16}$

\footnotetext{
${ }^{15}$ Of course, under other distributional assumptions, symmetric equilibria may exist in which Home always wins and foreign countries do not use dominated strategies. For example, if the distribution function is uniform and $b_{o}$ is small, then there exists a symmetric equilibrium in which Home bids $b_{H}=\omega(2)-\eta(2)$ and a foreign country of type $\zeta^{* j}$ bids $b\left(\zeta^{* j}\right)=\omega\left(\zeta^{* j}\right)-\eta\left(\zeta^{* j}\right)$, provided that the following parameter restriction is satsified: $\zeta_{H}-2+\left(4 \tau_{o}+3 \Delta\right) / 2>0$. Details are available from the authors.

${ }^{16}$ Related issues arise in other games. Consider, for example, a Bertrand pricing game, in which firm 1's constant unit cost is known to take value 1 while firm 2's constant unit cost is distributed over $[1,2]$. In any Nash equilibrium for this Bertrand game, firm 1 sets its price equal to 1 and wins all ties, while all types of firm 2 also select the price of 1 and lose the tie. (It can be shown that this conclusion holds also when it is allowed that firm 1 can use mixed strategies.) With the exception of the type for which cost equals 1, all types of firm 2 then use a dominated strategy. This equilibrium is analogous to that described in (6.1) for the auction game considered here.
} 
We now move to our third step and consider whether symmetric equilibria exist in which Home sometimes wins. Our finding is as follows:

Lemma 6.4: In any symmetric equilibrium of the extended auction, if $b_{o}$ is sufficiently close to zero, then Home cannot sometimes win.

The proof is in the Appendix. We sketch here the basic argument, which involves three steps. First, we show that it is impossible to have a pooling region over which foreign firms sometimes or always win, given that Home is allowed to bid in the extended auction. Second, we show that Home sometimes wins only if there exists $\widehat{\zeta}^{*} \in(1,2)$ such that $b\left(\widehat{\zeta}^{*}\right)=b_{H}$ and, for all $\zeta^{* j}>\widehat{\zeta}^{*}, b\left(\zeta^{* j}\right)>b_{H}$ and $b$ is strictly increasing. Third, we exploit the following tension. On the one hand, type $\widehat{\zeta}^{*}$ (perhaps plus $\epsilon$ ) has the option of mimicking lower types, and so must be indifferent between beating Home and not, indicating a relationship between $\omega\left(\widehat{\zeta}^{*}\right)$ and $\eta\left(\widehat{\zeta}^{*}\right)$. On the other hand, type $\widehat{\zeta}^{*}$ has the option of mimicking higher types, and so must be indifferent between bidding its equilibrium bid and that assigned to a slightly higher type, indicating a relationship between $\omega\left(\widehat{\zeta}^{*}\right)$ and $\lambda\left(\widehat{\zeta}^{*}\right)$. In our basic auction, as Lemmas 4.4 and 4.9 indicate, this tension is resolved with a pooling region at $b_{o}$. But in the extended auction, as established in the first step, we cannot have a pooling region over which foreign countries sometimes or always win. A contradiction is thus suggested.

We may now use Lemmas $6.1,6.2$ and 6.4 to conclude as follows:

Proposition 6.1: In any symmetric equilibrium of the extended auction, if $b_{o}$ is sufficiently close to zero, then Home always wins and bids $b_{H} \in\left[\omega(2)-\eta(2), \zeta^{H} \frac{\Delta}{4}\right]$. Furthermore, the resulting expected revenue is strictly greater than in the equilibrium outcome that occurs in the basic auction (as described in Propositions 4.1 and 4.2).

Proof: We need only confirm that expected revenue is higher in any symmetric equilibrium of the extended auction than in the symmetric equilibrium outcome of the basic auction. This is trivial to see. When Home is allowed to bid, Home always wins and the seller thus always gets $b_{H} \geq \omega(2)-\eta(2)$. By contrast, in the basic auction wherein Home does not bid, the seller sometimes (i.e., when there 
is no auction failure) gets

$$
b\left(\zeta^{* j}\right) \leq b(2)=\omega(2)-\lambda(2)-\frac{\Delta}{4} \int_{\bar{\zeta}^{*}}^{\zeta^{* j}} F(x) d x<\omega(2)-\lambda(2)<\omega(2)-\eta(2) .
$$

Thus, expected revenue is clearly higher when Home bids. Q.E.D.

The expected-revenue result is of particular importance. Intuitively, when $b_{o}$ is small so that Home is sure to bid, expected revenue rises relative to that achieved in the basic auction, because (i) auction failure is avoided, and (ii) Home bids more than would any foreign country were Home not allowed to bid.

\section{Policy: Revenue and Efficiency Criteria}

In this section we consider the normative implications of permitting Home to bid to retire the right of retaliation. We do so by comparing the basic and extended auctions under the alternative criteria of expected revenue and ex-ante efficiency.

\subsection{Revenue}

We first discuss the implications for expected revenue of permitting Home to bid to retire the right of retaliation. Greater expected revenue would naturally be viewed as a good thing from the point of view of the seller. Moreover, as discussed in the Introduction, part of the motivation for considering such auctions in the WTO is to enhance the ability of smaller, poorer countries to achieve some compensation in the event that a trading partner takes an action that nullifies or impairs their benefits within the WTO. From this perspective as well, expected revenue is a natural criterion for making normative comparisons across different auction designs.

If the desirability of permitting Home to bid is evaluated on the basis of expected revenue, Proposition 6.1 provides a clear normative conclusion: Home should be permitted to bid to retire the right of retaliation against it. This follows because, as Proposition 6.1 indicates, if $b_{o}$ is sufficiently small, Home always wins and the seller thus always gets $b_{H} \geq \omega(2)-\eta(2)$. By contrast, in the basic auction, the seller never receives a bid this high, and sometimes receives no bid at all. Therefore, if $b_{o}$ is sufficiently small, the seller's expected revenue is strictly higher when Home is allowed to bid. 
We observe as well that this normative conclusion is robust to a further extension of our auction games which allows for a "compensation" stage to precede the auction. Such an extension can be motivated by actual WTO practice, which typically encourages disputing parties to find a mutually agreeable form of compensation as a final means to avoid a retaliatory outcome (see note 8). To see that the conclusion holds in an extended game of this kind, let us suppose (i) that Home makes a take-it-or-leave-it compensation offer to the harmed country (i.e., the seller in any subsequent auction) which the harmed country either accepts or rejects, (ii) that a right of retaliation is granted to the harmed country (which it may subsequently auction off) if and only if the offer of compensation is rejected, and (iii) that both countries are risk neutral.

If the subsequent auction takes the form of our basic auction, then the seller's expected revenue from this auction is $2 P\left(b_{o}\right)$ (as defined in Lemma 4.10), and the harmed country would therefore accept nothing less than $2 P\left(b_{o}\right)$ as compensation. Home will offer to compensate the harmed country at the level $2 P\left(b_{o}\right)$ and foreclose the subsequent auction if and only if Home's payoff from doing so, $W_{N R}-2 P\left(b_{o}\right)$, is greater than its expected payoff under the basic auction, which is given by $F^{2}\left(\widetilde{\zeta}^{*}\right) W_{N R}+\left[1-F^{2}\left(\widetilde{\zeta}^{*}\right)\right] W_{R}$. We now report the following:

Lemma 7.1: For any $\zeta^{H} \geq 1$,

$$
W_{N R}-2 P\left(b_{o}\right)>F^{2}\left(\widetilde{\zeta}^{*}\right) W_{N R}+\left[1-F^{2}\left(\widetilde{\zeta}^{*}\right)\right] W_{R}
$$

The proof of this lemma is found in the Appendix. Lemma 7.1 implies that Home will indeed compensate the harmed country at the level $2 P\left(b_{o}\right)$ when the ensuing auction takes the form of our basic auction, thereby preventing the assignment of a retaliation right and foreclosing the subsequent auction. Hence, if the basic auction is preceded by a compensation stage as described above, the harmed country can expect to receive an amount of revenue equal to $2 P\left(b_{o}\right)$.

If the subsequent auction instead takes the form of the extended auction in which Home is permitted to bid, then with $b_{o}$ set sufficiently small Proposition 6.1 indicates that Home always wins and the seller thus always gets $b_{H} \in$ $\left[\omega(2)-\eta(2), \zeta^{H} \frac{\Delta}{4}\right]$ from this extended auction. Selecting an equilibrium of the extended auction determines a particular $b_{H}$ in this range, and under this equilibrium selection the harmed country would then accept nothing less than $b_{H}$ as compensation. As Home therefore pays $b_{H}$ to avoid retaliation whether this payment takes the form of compensation or rather takes the form of the winning bid in the ensuing auction, the harmed country will receive $b_{H}$ in any event when 
the auction permits Home bids. Hence, if the extended auction (with $b_{o}$ small) is preceded by a compensation stage as described above, the harmed country can expect to receive an amount of revenue equal to $b_{H} \in\left[\omega(2)-\eta(2), \zeta^{H} \frac{\Delta}{4}\right]$.

It may now be seen that the addition of a prior compensation stage does not change the basic normative conclusion of this subsection. Whether or not prior compensation is a viable option which is available to Home, if the desirability of permitting Home to bid is evaluated on the basis of expected revenue, Home should be permitted to bid to retire the right of retaliation against it. ${ }^{17}$

\subsection{Efficiency}

We next discuss the implications for ex-ante efficiency of permitting Home to bid to retire the right of retaliation. We define ex-ante efficiency according to the objective functions of the affected governments. If the WTO seeks to best serve the objectives of its member governments, then a normative case can be made for choosing among auction designs according to the criterion of ex-ante efficiency defined in this way.

In choosing between the basic and extended auctions, the affected governments include the Home government, the two foreign governments, and the seller (the harmed government). In our quasi-linear setting, ex-ante efficiency is achieved when the expected joint welfare among the four governments is maximized. We thus adopt as our normative criterion in this subsection the expected joint welfare of the affected governments.

A first observation is that, under this criterion, the expected revenue generated by each auction is irrelevant. This is because the revenue paid by the winning bidder to the seller is a pure transfer from one government to another, and such transfers cannot alter the joint surplus available to the Home government, the two foreign governments and the seller in our quasi-linear setting. Hence, when ex-ante efficiency is the criterion, expected revenue differences cannot be used to select among auction designs. Instead, differences in the allocation of the right of retaliation across auctions becomes the critical feature. Moreover, since the seller is only affected through the expected revenue, we may restrict our measure

\footnotetext{
${ }^{17}$ Note that, as we have modeled the prior compensation stage, Home would offer nothing to the harmed country in the manner of prior compensation if no auction were permitted, since by assumption the harmed country is itself unable to use the retaliation right against Home. In this way, the mere ability to auction the right of retaliation, whether in the basic or the extended auction setting, can help ensure that the harmed country receives compensation, even if the auction itself is foreclosed by the payment of prior compensation.
} 
of joint welfare to the sum of the (gross) welfare levels of the Home and the two foreign governments.

In this regard, it might be thought that any retaliation would reduce efficiency. This perspective suggests that it is desirable under the ex-ante efficiency criterion to permit Home to bid. It must be remembered, however, that we have allowed governments to be motivated by political-economy concerns, and so if a foreign country experiences a sufficiently large political-economy shock it might be efficient to permit that country to raise its tariff level (i.e., retaliate to $\tau_{o}+\Delta$ ). Hence, to assess whether the basic auction - which results in retaliation unless there is auction failure - can lead to greater ex-ante efficiency than the extended auction - which never results in retaliation for sufficiently small $b_{o}$ - we need to derive an expression for the expected joint welfare under each auction.

Consider first the extended auction. As just noted, for sufficiently small $b_{o}$ Home always makes the winning bid and retires the retaliation right. Hence, letting $E J H$ denote the expected joint welfare under the extended auction, recalling the definition of joint welfare $J\left(\tau^{* 1}, \tau^{* 2}\right)$ for any two tariffs $\tau^{* 1}$ and $\tau^{* 2}$, and letting $E J\left(\tau_{o}, \tau_{o}\right)$ denote the expected joint welfare when there is no retaliation (i.e., when $\tau^{* 1} \equiv \tau_{o}$ and $\tau^{* 2} \equiv \tau_{o}$ ), we have that, for sufficiently small $b_{o}$,

$$
E J H=E J\left(\tau_{o}, \tau_{o}\right) .
$$

We now develop an analogous expression for the basic auction. Using (3.2), (3.3) and (5.3), we note that when foreign country 1 wins the right to retaliate, joint welfare is given by

$$
\begin{aligned}
J\left(\tau_{o}+\Delta, \tau_{o}\right)= & J\left(\tau_{o}, \tau_{o}\right)+\left[\omega\left(\zeta^{* 1}\right)-\eta\left(\zeta^{* 1}\right)+\lambda\left(\zeta^{* 2}\right)-\eta\left(\zeta^{* 2}\right)+W_{R}-W_{N R}\right] \\
& =J\left(\tau_{o}, \tau_{o}\right)+\frac{\Delta}{8}\left[2\left(1-\zeta^{H}-\Delta\right)+\left(\zeta^{* 1}-\zeta^{* 2}\right)\right] .
\end{aligned}
$$

Similarly, when foreign country 2 wins, joint welfare is given by

$$
J\left(\tau_{o}, \tau_{o}+\Delta\right)=J\left(\tau_{o}, \tau_{o}\right)+\frac{\Delta}{8}\left[2\left(1-\zeta^{H}-\Delta\right)+\left(\zeta^{* 2}-\zeta^{* 1}\right)\right] .
$$

Finally, (7.1) and (7.2) imply that

$$
\frac{1}{2} J\left(\tau_{o}+\Delta, \tau_{o}\right)+\frac{1}{2} J\left(\tau_{o}, \tau_{o}+\Delta\right)=J\left(\tau_{o}, \tau_{o}\right)+\frac{\Delta}{8}\left[2\left(1-\zeta^{H}-\Delta\right)\right] .
$$


Let $E J B$ denote the expected joint welfare under the basic auction. Using (7.1), (7.2) and (7.3), and after some manipulation, we find that

$$
\begin{gathered}
E J B=E J\left(\tau_{o}, \tau_{o}\right)+\frac{\Delta}{4}\left\{\left[1-F^{2}\left(\widetilde{\zeta}^{*}\right)\right]\left[1-\zeta^{H}-\Delta\right]\right. \\
\left.\left.+\int_{\widetilde{\zeta}^{*}}^{\bar{\zeta}^{*}}\left[\int_{1}^{\widetilde{\zeta}^{*}}\left(\zeta-\zeta^{* 2}\right) F^{\prime}\left(\zeta^{* 2}\right) d \zeta^{* 2}\right] F^{\prime}(\zeta)\right) d \zeta+\int_{\bar{\zeta}^{*}}^{2}\left[\int_{1}^{\zeta}\left(\zeta-\zeta^{* 2}\right) F^{\prime}\left(\zeta^{* 2}\right) d \zeta^{* 2}\right] F^{\prime}(\zeta) d \zeta\right\} .
\end{gathered}
$$

Intuitively, the difference between the expected joint welfare under the basic auction $(E J B)$ and the expected joint welfare when there is no retaliation $\left(E J\left(\tau_{o}, \tau_{o}\right)\right)$ is composed of the sum of three terms, which can be understood with the help of (7.1)-(7.3). A first term $\left(\left[1-F^{2}\left(\widetilde{\zeta}^{*}\right)\right]\left[1-\zeta^{H}-\Delta\right]\right)$ represents the "baseline" expected efficiency loss from protection with $\zeta^{* 1} \equiv \zeta^{* 2}$. This term is strictly negative, and it appears in (7.1), (7.2) and (7.3), since some foreign country wins the right to retaliate in each expression. The second and third terms are each double integrals, and these terms represent the expected efficiency gain from allocating retaliation to the high- $\zeta^{* i}$ foreign country. These two terms are each strictly positive. The first double integral measures this expected gain when the high- $\zeta^{* i}$ foreign country lies in the range $\left[\widetilde{\zeta}^{*}, \bar{\zeta}^{*}\right]$ and the low- $\zeta^{* i}$ foreign country lies in the range $\left[1, \widetilde{\zeta}^{*}\right]$. Excluded from this double integral is the range of low$\zeta^{* i}$ realizations that lie above $\widetilde{\zeta}^{*}$ but below the realization of the high- $\zeta^{* i}$ foreign country. This is because there is pooling over this region in the basic auction, with each foreign country receiving the right of retaliation with probability $1 / 2$, and as indicated by (7.3) this pooling region adds no expected efficiency gain from allocating retaliation to the high- $\zeta^{* i}$ foreign country. The second double integral measures this expected gain when the high- $\zeta^{* i}$ foreign country lies in the range $\left[\bar{\zeta}^{*}, 2\right]$. There is no pooling in the basic auction when the high- $\zeta^{* i}$ foreign country lies in this range, and so the range of low- $\zeta^{* i}$ realizations runs from 1 up to the high- $\zeta^{* i}$ foreign country realization.

With expressions for the expected joint welfare under the basic and extended auctions given by $E J B$ and $E J H$, respectively, we may now state:

Proposition 7.1: If $1-\zeta^{H}-\Delta$ is sufficiently close to zero, then $E J B>E J H$. 
Proof: Under A4, $\bar{\zeta}^{*}<2$. The proposition thus follows as a direct consequence of the expressions for $E J B$ and $E J H$ provided above. Q.E.D.

Under our maintained assumptions, this proposition describes a parameter region in which $\zeta^{H} \in[1,2]$ is equal to or near unity, $\Delta>0$ is near zero, and $b_{o} \geq 0$ is equal to or near zero (so that A4 holds, even though $\Delta$ is small). For example, our maintained assumptions and the additional assumption in Proposition 7.1 all hold if $\zeta^{H}=1, b_{o}=0$, and $\Delta>0$ is sufficiently small.

According to Proposition 7.1, greater ex-ante efficiency is achieved under the basic auction than under the extended auction (for small $b_{o}$ ) if Home's politicaleconomy weight is small (i.e. $\zeta^{H}$ is close to one) and the degree of retaliation being auctioned is small (i.e., $\Delta$ close to zero). Under these conditions, the expected benefit of allocating the retaliation right to the foreign country that experiences the biggest political-economy shock outweighs the expected cost imposed on the other two countries, and so expected joint welfare is higher under the basic auction than under the extended auction, where the right of retaliation is surely retired.

If the desirability of permitting Home to bid is evaluated on the basis of exante efficiency, Proposition 7.1 therefore provides a clear normative conclusion (at least for $b_{o}$ small): Home should not be permitted to bid to retire the right of retaliation against it unless the political costs of retaliation against Home $\left(\zeta^{H}\right)$ and/or the size of the retaliation $(\Delta)$ are sufficiently large. We observe that, for the described parameter ranges, this normative conclusion is directly opposed to the conclusion reported in the previous subsection when the criterion is instead expected revenue. More broadly, these findings indicate that the desirability of key auction features will depend generally on what is perceived to be the purpose of introducing auctions in the WTO-retaliation setting.

Finally, we note that the issue of whether prior compensation is a viable option available to Home can have important normative implications for the ex-ante efficiency of the basic auction. As Proposition 7.1 indicates, there are conditions under which the allocation of retaliation rights under the basic auction improves ex-ante efficiency relative to the certain retirement of the right to retaliate under the extended auction. But as Lemma 7.1 indicates, when a compensation stage precedes the basic auction, Home always makes a compensation offer which the harmed country is certain to accept. Hence, by leading to certain retirement of the right to retaliate, the presence of a viable prior compensation stage can actually reduce ex-ante efficiency in the basic auction setting (to the level of exante efficiency achieved in the extended auction). More broadly, this suggests that the compensation provisions of the WTO can have important links with 
the performance of auctions of WTO retaliation rights, at least when ex-ante efficiency is the concern, and that a more complete understanding of the impact of permitting retaliation rights to be auctioned in the WTO may require a better understanding of the workings of WTO compensation provisions. ${ }^{18}$

\section{Conclusion}

We offer a first formal analysis of the possibility that retaliation rights within the WTO system might be allocated through auctions. We focus here on firstprice sealed-bid auctions. In our basic auction, two foreign countries bid for the right to retaliate against the home country. The basic auction is characterized by positive externalities, since retaliation by one foreign country improves the terms of trade for the other foreign country. We show that this auction exhibits some unusual properties: the retaliation right may be misallocated across the foreign countries, and it is also possible that auction failure occurs. We then consider an extended auction, in which the home country is also allowed to bid to retire the right of retaliation. The extended auction is again characterized by positive externalities between foreign countries. But the extended auction also features negative externalities, since the home country experiences a negative externality whenever a foreign country wins. In the extended auction, we find that auction failure does not occur; in fact, the home country always wins and the retaliation right is therefore always retired.

We also evaluate the different auction formats from normative standpoints. The extended auction generates greater expected revenue for the seller than does the basic auction. On the other hand, the basic auction may be preferred under an efficiency criterion. As a general matter, our analysis thus suggests that the desirability of key auction design features may hinge on the purpose that auctions are expected to serve in the WTO-retaliation setting.

\footnotetext{
${ }^{18}$ While our auction models predict that Home would always offer enough cash compensation in a prior compensation stage to foreclose (the auction and thus) retaliation against it, in practice governments rarely settle WTO disputes through the payment of cash compensation. A possible interpretation is that in practice it is often efficient to have retaliation occur (i.e., the disputing governments cannot settle on an amount of compensation that both would agree is better than a retaliatory outcome). In this light, the effect of the positive externality across foreign bidders in holding bids below their true valuation is what, in our auction models, ensures that Home always finds it worthwhile to "outbid" the foreign bidders and retire the right of retaliation, even when this is not efficient (i.e., even when it would be more valuable for one of the foreign countries to exercise the retaliation right than for Home to retire it).
} 


\section{Appendix}

Proof of Lemma 4.1: To prove this lemma, fix a symmetric equilibrium. Suppose that $\zeta_{B}^{* j}>\zeta_{S}^{* j}$ and $b\left(\zeta_{S}^{* j}\right) \neq N$. Let $\rho\left(\zeta^{* j}\right)$ denote the probability that foreign country $j$ wins when it bids $b\left(\zeta^{* j}\right)$. Let $\mathbf{B} \equiv \operatorname{prob}\left\{b\left(\zeta^{* j}\right) \neq N\right\}$.

We first show part (i). Given $b\left(\zeta_{S}^{* j}\right) \neq N$, incentive compatibility implies

$$
\rho\left(\zeta_{S}^{* j}\right)\left[\omega\left(\zeta_{S}^{* j}\right)-b\left(\zeta_{S}^{* j}\right)\right]+\left(1-\rho\left(\zeta_{S}^{* j}\right)\right) \lambda\left(\zeta_{S}^{* j}\right) \geq \mathbf{B} \lambda\left(\zeta_{S}^{* j}\right)+(\mathbf{1}-\mathbf{B}) \eta\left(\zeta_{S}^{* j}\right),
$$

which is to say that type $\zeta_{S}^{* j}$ must (weakly) prefer $b\left(\zeta_{S}^{* j}\right)$ to $N$. Now, suppose to the contrary that $b\left(\zeta_{B}^{* j}\right)=N$. Then type $\zeta_{B}^{* j}$ must (weakly) prefer $N$ to $b\left(\zeta_{S}^{* j}\right)$ :

$$
\mathbf{B} \lambda\left(\zeta_{B}^{* j}\right)+(\mathbf{1}-\mathbf{B}) \eta\left(\zeta_{B}^{* j}\right) \geq \rho\left(\zeta_{S}^{* j}\right)\left[\omega\left(\zeta_{B}^{* j}\right)-b\left(\zeta_{S}^{* j}\right)\right]+\left(1-\rho\left(\zeta_{S}^{* j}\right)\right) \lambda\left(\zeta_{B}^{* j}\right) .
$$

Adding (9.1) and (9.2) gives

$$
\begin{aligned}
& \mathbf{B}\left[\lambda\left(\zeta_{B}^{* j}\right)-\lambda\left(\zeta_{S}^{* j}\right)\right]+(\mathbf{1}-\mathbf{B})\left[\eta\left(\zeta_{B}^{* j}\right)-\eta\left(\zeta_{S}^{* j}\right)\right] \\
\geq & \rho\left(\zeta_{S}^{* j}\right)\left[\omega\left(\zeta_{B}^{* j}\right)-\omega\left(\zeta_{S}^{* j}\right)\right]+\left(1-\rho\left(\zeta_{S}^{* j}\right)\right)\left[\lambda\left(\zeta_{B}^{* j}\right)-\lambda\left(\zeta_{S}^{* j}\right)\right] .
\end{aligned}
$$

Using (3.6), we may rewrite (9.3) as

$$
\mathbf{B}[1-\Delta]+(\mathbf{1}-\mathbf{B}) \geq \rho\left(\zeta_{S}^{* j}\right)[1+\Delta]+\left(1-\rho\left(\zeta_{S}^{* j}\right)\right)[1-\Delta],
$$

which in turn may be simplified as

$$
\frac{1-\mathbf{B}}{2} \geq \rho\left(\zeta_{S}^{* j}\right)
$$

Now, we also know that

$$
\rho\left(\zeta_{S}^{* j}\right) \geq 1-\mathbf{B},
$$

since the probability of winning with $b\left(\zeta_{S}^{* j}\right)$ is at least the probability that the rival foreign country does not bid (in which case a bid of $b\left(\zeta_{S}^{* j}\right)$ certainly wins). Clearly, if $\mathbf{B}<\mathbf{1}$, then (9.4) and (9.5) are contradictory.

Finally, if $\mathbf{B}=\mathbf{1}$, so that the set of non-bidding types is of measure zero, then (9.4) and (9.5) imply that type $\zeta_{S}^{* j}$ must lose: $\rho\left(\zeta_{S}^{* j}\right)=0$. We thus may find a type $\zeta_{M}^{* j} \in\left(\zeta_{S}^{* j}, \zeta_{B}^{* j}\right)$ that bids and sometimes wins: $\rho\left(\zeta_{M}^{* j}\right)>0$. Given that $b\left(\zeta_{M}^{* j}\right) \neq N$, incentive compatibility implies that

$$
\rho\left(\zeta_{M}^{* j}\right)\left[\omega\left(\zeta_{M}^{* j}\right)-b\left(\zeta_{M}^{* j}\right)\right]+\left(1-\rho\left(\zeta_{M}^{* j}\right)\right) \lambda\left(\zeta_{M}^{* j}\right) \geq \mathbf{B} \lambda\left(\zeta_{M}^{* j}\right)+(\mathbf{1}-\mathbf{B}) \eta\left(\zeta_{M}^{* j}\right),
$$


which is to say that type $\zeta_{M}^{* j}$ must (weakly) prefer $b\left(\zeta_{M}^{* j}\right)$ to $N$. But $\mathbf{B}=\mathbf{1}$ and (3.6) then imply that

$$
\rho\left(\zeta_{M}^{* j}\right)\left[\omega\left(\zeta_{B}^{* j}\right)-b\left(\zeta_{M}^{* j}\right)\right]>\rho\left(\zeta_{M}^{* j}\right) \lambda\left(\zeta_{B}^{* j}\right),
$$

and thus type $\zeta_{B}^{* j}$ strictly prefers $b\left(\zeta_{M}^{* j}\right)$ to $N$, which is again a contradiction.

We now prove part (ii). Given that $\zeta_{B}^{* j}>\zeta_{S}^{* j}$ and $b\left(\zeta_{S}^{* j}\right) \neq N$, we have from part (i) that $b\left(\zeta_{B}^{* j}\right) \neq N$. Incentive compatibility thus implies

$$
\begin{aligned}
& \rho\left(\zeta_{B}^{* j}\right)\left[\omega\left(\zeta_{B}^{* j}\right)-b\left(\zeta_{B}^{* j}\right)\right]+\left(1-\rho\left(\zeta_{B}^{* j}\right)\right) \lambda\left(\zeta_{B}^{* j}\right) \\
\geq & \rho\left(\zeta_{S}^{* j}\right)\left[\omega\left(\zeta_{B}^{* j}\right)-b\left(\zeta_{S}^{* j}\right)\right]+\left(1-\rho\left(\zeta_{S}^{* j}\right)\right) \lambda\left(\zeta_{B}^{* j}\right)
\end{aligned}
$$

and

$$
\begin{aligned}
& \rho\left(\zeta_{S}^{* j}\right)\left[\omega\left(\zeta_{S}^{* j}\right)-b\left(\zeta_{S}^{* j}\right)\right]+\left(1-\rho\left(\zeta_{S}^{* j}\right)\right) \lambda\left(\zeta_{S}^{* j}\right) \\
\geq & \rho\left(\zeta_{B}^{* j}\right)\left[\omega\left(\zeta_{S}^{* j}\right)-b\left(\zeta_{B}^{* j}\right)\right]+\left(1-\rho\left(\zeta_{B}^{* j}\right)\right) \lambda\left(\zeta_{S}^{* j}\right) .
\end{aligned}
$$

Adding (9.6) and (9.7), we obtain

$$
\left[\rho\left(\zeta_{B}^{* j}\right)-\rho\left(\zeta_{S}^{* j}\right)\right]\left[\omega\left(\zeta_{B}^{* j}\right)-\lambda\left(\zeta_{B}^{* j}\right)\right] \geq\left[\rho\left(\zeta_{B}^{* j}\right)-\rho\left(\zeta_{S}^{* j}\right)\right]\left[\omega\left(\zeta_{S}^{* j}\right)-\lambda\left(\zeta_{S}^{* j}\right)\right] .
$$

Since $\omega-\lambda$ is strictly increasing, it follows from (9.8) that $\rho\left(\zeta_{B}^{* j}\right) \geq \rho\left(\zeta_{S}^{* j}\right)$ and thus, equivalently, that $b\left(\zeta_{B}^{* j}\right) \geq b\left(\zeta_{S}^{* j}\right)$. Q.E.D.

Proof of Lemma 4.4: We establish the lemma by proving a sequence of claims:

Claim 1: In any symmetric equilibrium, if $2 \geq \zeta_{B}^{* j}>\zeta_{S}^{* j} \geq 1$ and $b\left(\zeta^{* j}\right) \equiv \widetilde{b} \geq b_{o}$ for all $\zeta^{* j} \in\left[\zeta_{S}^{* j}, \zeta_{B}^{* j}\right]$, then $\widetilde{b}=b_{o}$.

To prove this claim, we suppose to the contrary that $b\left(\zeta^{* j}\right) \equiv \widetilde{b}>b_{o}$ for $\zeta^{* j} \in$ $\left[\zeta_{S}^{* j}, \zeta_{B}^{* j}\right]$, where $2 \geq \zeta_{B}^{* j}>\zeta_{S}^{* j} \geq 1$. There are two subcases.

First, suppose that $\omega(2)-\widetilde{b} \leq \lambda(2)$. It then follows that $\omega\left(\zeta_{S}^{* j}\right)-\widetilde{b}<\lambda\left(\zeta_{S}^{* j}\right)$. Hence, type $\zeta_{S}^{* j}$ as well as an interval of types just above $\zeta_{S}^{* j}$ would strictly gain from deviating to $\widetilde{b}-\epsilon \geq b_{o}$, for $\epsilon$ positive and small. With positive probability, the other country bids $\widetilde{b}$, and such a deviation then converts ties into losses, resulting in a strict gain. If the other country bids more than $\widetilde{b}$, then the deviation is irrelevant. Finally, if the other country bids less than $\widetilde{b}$, then the deviation converts wins into losses (when the other country's bid falls between the deviant bid and $\widetilde{b}$ ) or results 
in a win with a lower bid (when the other country's bid falls below the deviant bid). In either case, the deviation results in a strict gain.

Second, suppose that $\omega(2)-\widetilde{b}>\lambda(2)$. Then there exists some value $\zeta_{z}^{* j} \in(1,2)$ such that $\omega\left(\zeta_{z}^{* j}\right)-\widetilde{b}=\lambda\left(\zeta_{z}^{* j}\right)$. Of course, not every type in $\left[\zeta_{S}^{* j}, \zeta_{B}^{* j}\right]$ can be $\zeta_{z}^{* j}$; thus, there exists a sub-interval of types, $\left(\underline{\zeta}_{z}^{* j}, \bar{\zeta}_{z}^{* j}\right) \subset\left[\zeta_{S}^{* j}, \zeta_{B}^{* j}\right]$ over which (i) $\omega\left(\zeta^{* j}\right)-\widetilde{b}>\lambda\left(\zeta^{* j}\right)$ or (ii) $\omega\left(\zeta^{* j}\right)-\widetilde{b}<\lambda\left(\zeta^{* j}\right)$. Consider case (i). Any type $\zeta^{* j} \in\left(\underline{\zeta}_{z}^{* j}, \bar{\zeta}_{z}^{* j}\right)$ would then strictly gain by deviating to $\widetilde{b}+\epsilon$, converting ties to wins. Likewise, in case (ii), such types would strictly gain by deviating to $\widetilde{b}-\epsilon \geq b_{o}$, converting ties to losses. This proves Claim 1 .

Claim 2: In any symmetric equilibrium, there exists $\bar{\epsilon} \in\left(0,2-\zeta_{L}^{*}\right]$ such that $b\left(\zeta^{* j}\right)=b_{o}$ for all $\zeta^{* j} \in\left(\zeta_{L}^{*}, \zeta_{L}^{*}+\bar{\epsilon}\right]$.

To prove this claim, we suppose to the contrary that $b$ is strictly increasing at $\zeta_{L}^{*}$. By Lemma 4.3, we know that $b\left(\zeta^{* j}\right) \neq N$ for all $\zeta^{* j} \in\left(\zeta_{L}^{*}, 2\right]$. Further, Lemma 4.1 indicates that $b$ cannot decrease; thus, $b\left(\zeta^{* j}\right)>b_{o}$ for all $\zeta^{* j} \in\left(\zeta_{L}^{*}, 2\right]$. By Claim 1 , it thus follows that pooling does not occur anywhere over $\zeta^{* j} \in\left(\zeta_{L}^{*}, 2\right]$. Hence, $b$ is strictly increasing over $\zeta^{* j} \in\left(\zeta_{L}^{*}, 2\right]$.

For simplicity, let us assume that type $\zeta_{L}^{*}$ bids. Given that $b$ is strictly increasing throughout the bidding region, type $\zeta_{L}^{*}$ wins only when the other country does not bid. It follows that $b\left(\zeta_{L}^{*}\right)=b_{o}$ is necessary. It is also necessary that type $\zeta_{L}^{*}$ is indifferent between bidding and not bidding; thus, it must be that

$$
\mathbf{B} \lambda\left(\zeta_{L}^{*}\right)+(1-\mathbf{B})\left[\omega\left(\zeta_{L}^{*}\right)-b_{o}\right]=\mathbf{B} \lambda\left(\zeta_{L}^{*}\right)+(1-\mathbf{B}) \eta\left(\zeta_{L}^{*}\right),
$$

or equivalently

$$
\omega\left(\zeta_{L}^{*}\right)-b_{o}=\eta\left(\zeta_{L}^{*}\right)
$$

since $\mathbf{B}<1$ follows from Lemma 4.2.

Finally, it is also necessary that types higher than $\zeta_{L}^{*}$ are unable to gain through deviations. But (9.9) implies that

$$
\omega\left(\zeta_{L}^{*}\right)-b_{o}<\lambda\left(\zeta_{L}^{*}\right)
$$

Given that payoffs are continuous, it follows from (9.10) that $\omega\left(\zeta_{L}^{*}+\epsilon\right)-b_{o}<$ $\lambda\left(\zeta_{L}^{*}+\epsilon\right)$, for $\epsilon$ positive and small. As $b\left(\zeta_{L}^{*}+\epsilon\right)>b_{o}$, it follows that

$$
\omega\left(\zeta_{L}^{*}+\epsilon\right)-b\left(\zeta_{L}^{*}+\epsilon\right)<\lambda\left(\zeta_{L}^{*}+\epsilon\right) .
$$


Thus, type $\zeta_{L}^{*}+\epsilon$ prefers losing to winning. As a consequence, it would strictly gain by deviating and bidding less. ${ }^{19}$

We have now constructed an interval of types that would deviate and bid less. This is a contradiction, and so our supposition that $b$ is strictly increasing at $\zeta_{L}^{*}$ must be false. Hence, a region of pooling must begin at $\zeta_{L}^{*}$. By Claim 1, we know that pooling must occur at the reserve bid, $b_{o}$. This establishes Claim 2.

Claim 3: In any symmetric equilibrium, $b(2)>b_{o}$.

Suppose to the contrary that $b(2)=b_{o}$. By Claim 2, pooling occurs at $b_{o}$ for all types $\zeta^{* j} \in\left(\zeta_{L}^{*}, 2\right]$. Consider type $\zeta^{* j}=2$. This type receives payoff $\left[\frac{\mathrm{B}}{2}+1-\right.$ $\mathbf{B}]\left(\omega(2)-b_{o}\right)+\frac{\mathbf{B}}{2} \lambda(2)$, where $\mathbf{B}=1-F\left(\zeta_{L}^{*}\right) \in(0,1)$. If type $\zeta^{* j}=2$ were to deviate and bid $b_{o}+\epsilon$, for $\epsilon$ positive and small, it would receive payoff $\omega(2)-b_{o}-\epsilon$. The gain from this deviation is

$$
\frac{\mathbf{B}}{2}\left[\omega(2)-b_{o}-\lambda(2)\right]-\epsilon>0,
$$

where the inequality follows for $\epsilon$ small, given $\mathbf{A} 4$ and $\mathbf{B} \in(0,1)$. To prevent deviations by higher types, therefore, it is necessary that pooling does not extend throughout the support. This proves Claim 3.

Together, the three claims establish that a region of pooling must begin at $\zeta_{L}^{*}$. The pooling occurs at the reserve bid, $b_{o}$, and it does not include the highest types. Given that $b$ is (weakly) increasing by Lemma 4.1, it follows that $b$ exceeds $b_{o}$ for higher types. The necessary existence of $\zeta_{H}^{*} \in\left(\zeta_{L}^{*}, 2\right)$ is thus established, and the lemma is proved. Q.E.D.

Proof of Lemma 4.5: To prove this lemma, we recall from Lemma 4.4 that $b\left(\zeta^{* j}\right)>b_{o}$ for $\zeta^{* j}>\zeta_{H}^{*}$, where $\zeta_{H}^{*} \in\left(\zeta_{L}^{*}, 2\right)$. By Lemma 4.1 and Claim $1, b$ is strictly increasing for $\zeta^{* j}>\zeta_{H}^{*}$. Suppose $b\left(\zeta_{H}^{*}\right)>b_{o}$. Then type $\zeta_{H}^{*}$ would strictly gain by deviating to $b^{\prime} \in\left(b_{o}, b\left(\zeta_{H}^{*}\right)\right)$, since it preserves its win-loss probabilities but now wins with a lower bid. Thus, it is necessary that $b\left(\zeta_{H}^{*}\right)=b_{o}$. Finally, suppose there is a discontinuity at some value $\zeta_{d}^{*} \in\left[\zeta_{H}^{*}, 2\right]$. For simplicity, suppose that $b$ contains its upward jump, so that $\lim _{\epsilon \rightarrow 0} b\left(\zeta_{d}^{*}+\epsilon\right)=b\left(\zeta_{d}^{*}\right)$. Then type $\zeta_{d}^{*}$ would

\footnotetext{
${ }^{19}$ In the event that the rival bids more than $b\left(\zeta_{L}^{*}+\epsilon\right)$, type $\zeta_{L}^{*}+\epsilon$ loses and enjoys payoff $\lambda\left(\zeta_{L}^{*}+\epsilon\right)$ whether or not it deviates; in the event that the rival doesn't bid or bids less than the deviant bid, type $\zeta_{L}^{*}+\epsilon$ gains from deviating since it wins with a lower bid; and in the event that the rival bid falls between $b\left(\zeta_{L}^{*}+\epsilon\right)$ and the deviant bid, type $\zeta_{L}^{*}+\epsilon$ gains from deviating since it prefers losing to winning with the bid $b\left(\zeta_{L}^{*}+\epsilon\right)$.
} 
strictly gain from a deviation to a lower bid that rests in the gap, as it would thereby preserve its win-loss probabilities while winning with a lower bid. Thus, $b\left(\zeta^{* j}\right)$ is continuous for $\zeta^{* j} \geq \zeta_{H}^{*}$. Q.E.D.

Proof of Lemma 4.6: Using (3.5), it is straightforward to show that (4.1) holds if and only if $\bar{\zeta}^{*}\left(b_{o}\right)$ takes the form given in (4.2). Clearly, $\bar{\zeta}^{*}\left(b_{o}\right)>1$. It remains to show that $\bar{\zeta}^{*}\left(b_{o}\right)<2$. Using A4 and (3.5), observe that

$$
2-\bar{\zeta}^{*}\left(b_{o}\right)=1-\left(4 \tau_{o}+2 \Delta+\frac{4}{\Delta} b_{o}\right)>1-\left[4 \tau_{o}+2 \Delta+\frac{4}{\Delta}(\omega(2)-\lambda(2))\right]=0,
$$

which establishes the lemma. Q.E.D.

Proof of Lemma 4.7: Referring to (4.3), observe that $L H S\left(\zeta^{* j}=\bar{\zeta}^{*}\right)=0<$ $\operatorname{RHS}\left(\zeta^{* j}=\bar{\zeta}^{*}\right)$, where the inequality follows since $F\left(\bar{\zeta}^{*}\right)>0$ by Lemma 4.6 and $\omega\left(\bar{\zeta}^{*}\right)-b_{o}-\eta\left(\bar{\zeta}^{*}\right)>\omega\left(\bar{\zeta}^{*}\right)-b_{o}-\lambda\left(\bar{\zeta}^{*}\right)=0$. Next, observe that $\operatorname{LH} S\left(\zeta^{* j}=1\right)>$ $0=R H S\left(\zeta^{* j}=1\right)$, where the inequality follows since $F\left(\bar{\zeta}^{*}\right)-F(1)=F\left(\bar{\zeta}^{*}\right)>0$ by Lemma 4.6 and $\lambda(1)-\left(\omega(1)-b_{o}\right)>0$. Given the continuity of the functions in $(4.3)$, it now follows that a solution $\widetilde{\zeta}^{*}\left(b_{o}\right)$ exists with $\widetilde{\zeta}^{*}\left(b_{o}\right) \in\left(1, \bar{\zeta}^{*}\left(b_{o}\right)\right)$.

To show that this solution is unique, we show that $\operatorname{LHS}\left(\zeta^{* j}\right)-R H S\left(\zeta^{* j}\right)$ is strictly decreasing. Using (3.6), we find that

$$
\begin{gathered}
\frac{d\left[L H S\left(\zeta^{* j}\right)-R H S\left(\zeta^{* j}\right)\right]}{d \zeta^{* j}}= \\
F\left(\bar{\zeta}^{*}\right)\left[\frac{\lambda^{\prime}\left(\zeta^{* j}\right)-\omega^{\prime}\left(\zeta^{* j}\right)}{2}\right]-F^{\prime}\left(\zeta^{* j}\right)\left[\frac{\omega\left(\zeta^{* j}\right)-b_{o}+\lambda\left(\zeta^{* j}\right)-2 \eta\left(\zeta^{* j}\right)}{2}\right]<0,
\end{gathered}
$$

where the inequality follows since $F\left(\bar{\zeta}^{*}\right)>0$ by Lemma $4.6, \lambda^{\prime}\left(\zeta^{* j}\right)<\omega^{\prime}\left(\zeta^{* j}\right)$, $F^{\prime}\left(\zeta^{* j}\right)>0$ and

$$
\omega\left(\zeta^{* j}\right)-b_{o}+\lambda\left(\zeta^{* j}\right)-2 \eta\left(\zeta^{* j}\right)>0 .
$$

To see that the latter inequality holds, observe that the expression is constant in $\zeta^{* j}$, since $\omega^{\prime}\left(\zeta^{* j}\right)+\lambda^{\prime}\left(\zeta^{* j}\right)-2 \eta^{\prime}\left(\zeta^{* j}\right)=0$. It is sufficient, therefore, to show that the inequality holds at $\zeta^{* j}=2$. To see this, we observe that

$$
\omega(2)-b_{o}+\lambda(2)-2 \eta(2)>\omega(2)-b_{o}-\lambda(2)>0,
$$


where the former inequality uses $\lambda(2)>\eta(2)$ and the latter inequality uses A4.

Finally, we establish that $\widetilde{\zeta}^{*}\left(b_{o}\right)$ is strictly increasing. To this end, we use (4.3) and compute that

$$
\frac{d \widetilde{\zeta}^{*}}{d b_{o}}=-\frac{1}{2} \frac{\left[F\left(\bar{\zeta}^{*}\right)+F\left(\widetilde{\zeta}^{*}\right)\right]+F^{\prime}\left(\bar{\zeta}^{*}\right)\left[\lambda\left(\widetilde{\zeta}^{*}\right)-\left(\omega\left(\widetilde{\zeta}^{*}\right)-b_{o}\right)\right] \frac{d \bar{\zeta}^{*}}{d b_{o}}}{\frac{d\left[L H S\left(\zeta^{* j}\right)-R H S\left(\zeta^{* j}\right)\right]}{d \zeta^{* j}}}
$$

where the denominator is evaluated at $\zeta^{* j}=\widetilde{\zeta}^{*}$. Our work just above establishes that the denominator is negative. To see that the numerator is positive, observe that $F\left(\bar{\zeta}^{*}\right)+F\left(\widetilde{\zeta}^{*}\right)>0\left(\right.$ since $\left.\bar{\zeta}^{*}>\widetilde{\zeta}^{*}>1\right), F^{\prime}\left(\bar{\zeta}^{*}\right)>0, \frac{\partial \bar{\zeta}^{*}}{\partial b_{o}}=\frac{4}{\Delta}>0($ using (4.2)), and $\lambda\left(\widetilde{\zeta}^{*}\right)-\left(\omega\left(\widetilde{\zeta}^{*}\right)-b_{o}\right)>\lambda\left(\bar{\zeta}^{*}\right)-\left(\omega\left(\bar{\zeta}^{*}\right)-b_{o}\right)=0\left(\right.$ since $\left.\bar{\zeta}^{*}>\widetilde{\zeta}^{*}\right)$. Q.E.D.

Proof of Lemma 4.8: Fix a symmetric equilibrium. Consider type $\zeta_{H}^{*}$. This type could choose bid $b_{o}$ and thus tie with the bids of an interval of the rival country's types. Alternatively, with an arbitrarily small increase in its bid, if could select bid $b_{o}+\epsilon$, thereby receiving essentially the same payoff when the rival country bids above $b_{o}$ or elects not to bid. With the latter choice, however, type $\zeta_{H}^{*}$ wins rather than ties when the rival country bids $b_{o}$. Given the continuity of the payoff functions, since types just below (above) $\zeta_{H}^{*}$ choose to bid $b_{o}$ (just above $b_{o}$ ), type $\zeta_{H}^{*}$ must be indifferent between the alternatives. Thus, it is necessary that the payoff to type $\zeta_{H}^{*}$ from bidding $b_{o}$,

$$
F\left(\zeta_{L}^{*}\right)\left(\omega\left(\zeta_{H}^{*}\right)-b_{o}\right)+\frac{F\left(\zeta_{H}^{*}\right)-F\left(\zeta_{L}^{*}\right)}{2}\left(\omega\left(\zeta_{H}^{*}\right)-b_{o}+\lambda\left(\zeta_{H}^{*}\right)\right)+\left(1-F\left(\zeta_{H}^{*}\right)\right) \lambda\left(\zeta_{H}^{*}\right),
$$

must be the same as the payoff to type $\zeta_{H}^{*}$ from bidding $b_{o}$ plus an arbitrarily small increment,

$$
F\left(\zeta_{L}^{*}\right)\left(\omega\left(\zeta_{H}^{*}\right)-b_{o}\right)+\left(F\left(\zeta_{H}^{*}\right)-F\left(\zeta_{L}^{*}\right)\right)\left(\omega\left(\zeta_{H}^{*}\right)-b_{o}\right)+\left(1-F\left(\zeta_{H}^{*}\right)\right) \lambda\left(\zeta_{H}^{*}\right) .
$$

Indifference is thus obtained if and only if $\left[\omega\left(\zeta_{H}^{*}\right)-b_{o}+\lambda\left(\zeta_{H}^{*}\right)\right] / 2=\omega\left(\zeta_{H}^{*}\right)-b_{o}$, or equivalently $\omega\left(\zeta_{H}^{*}\right)-\lambda\left(\zeta_{H}^{*}\right)=b_{o}$. By $(4.1), \zeta_{H}^{*}=\bar{\zeta}^{*}\left(b_{o}\right)$ is necessary.

Consider next type $\zeta_{L}^{*}$. This type must be indifferent between not bidding and selecting the bid $b_{o}$. Thus, it is necessary that the payoff to type $\zeta_{L}^{*}$ of not bidding,

$$
F\left(\zeta_{L}^{*}\right) \eta\left(\zeta_{L}^{*}\right)+\left(1-F\left(\zeta_{L}^{*}\right)\right) \lambda\left(\zeta_{L}^{*}\right)
$$


must equal the payoff to type $\zeta_{L}^{*}$ from bidding $b_{o}$,

$$
F\left(\zeta_{L}^{*}\right)\left(\omega\left(\zeta_{L}^{*}\right)-b_{o}\right)+\frac{F\left(\zeta_{H}^{*}\right)-F\left(\zeta_{L}^{*}\right)}{2}\left(\omega\left(\zeta_{L}^{*}\right)-b_{o}+\lambda\left(\zeta_{L}^{*}\right)\right)+\left(1-F\left(\zeta_{H}^{*}\right)\right) \lambda\left(\zeta_{L}^{*}\right) .
$$

Equating this expressions and simplifying, we obtain

$$
\left(F\left(\zeta_{H}^{*}\right)-F\left(\zeta_{L}^{*}\right)\right)\left[\frac{\lambda\left(\zeta_{L}^{*}\right)-\left(\omega\left(\zeta_{L}^{*}\right)-b_{o}\right)}{2}\right]=F\left(\zeta_{L}^{*}\right)\left[\omega\left(\zeta_{L}^{*}\right)-b_{o}-\eta\left(\zeta_{L}^{*}\right)\right] .
$$

Next, we recall from above that $\zeta_{H}^{*}=\bar{\zeta}^{*}\left(b_{o}\right)$ is necessary. Referring to (4.3), we thus see that $\zeta_{L}^{*}=\widetilde{\zeta}^{*}\left(b_{o}\right)$ is necessary. Q.E.D.

Proof of Lemma 4.9: To establish this lemma, we use (4.4) and (4.6) and rewrite the local incentive constraint as follows:

$$
F^{\prime}\left(\zeta^{* j}\right)\left[\omega\left(\zeta^{* j}\right)-\lambda\left(\zeta^{* j}\right)\right]=\frac{d\left[F\left(\zeta^{* j}\right) b\left(\zeta^{* j}\right)\right]}{d \zeta^{* j}} .
$$

We follow standard arguments (see, e.g., Riley and Samuelson (1981)). To begin, we integrate both sides and rearrange terms, obtaining that the expected payment of type $\zeta^{* j} \in\left[\zeta_{H}^{*}, 2\right]$ must be

$$
F\left(\zeta^{* j}\right) b\left(\zeta^{* j}\right)=F\left(\bar{\zeta}^{*}\right) b\left(\bar{\zeta}^{*}\right)+\int_{\bar{\zeta}^{*}}^{\zeta^{* j}} F^{\prime}(x)[\omega(x)-\lambda(x)] d x .
$$

But we also know from Lemmas 4.5 and 4.8 that $b\left(\bar{\zeta}^{*}\right)=b_{o}$ is also necessary. Thus, using (9.13), we conclude that, in any symmetric equilibrium, the expected payment of type $\zeta^{* j} \in\left[\zeta_{H}^{*}, 2\right]$ must be

$$
F\left(\zeta^{* j}\right) b\left(\zeta^{* j}\right)=F\left(\bar{\zeta}^{*}\right) b_{o}+\int_{\bar{\zeta}^{*}}^{\zeta^{* j}} F^{\prime}(x)[\omega(x)-\lambda(x)] d x .
$$

We next integrate by parts and use (4.1), finding that

$$
\int_{\bar{\zeta}^{*}}^{\zeta^{* j}} F^{\prime}(x)[\omega(x)-\lambda(x)] d x
$$




$$
=F\left(\zeta^{* j}\right)\left[\omega\left(\zeta^{* j}\right)-\lambda\left(\zeta^{* j}\right)\right]-F\left(\bar{\zeta}^{*}\right) b_{0}-\frac{\Delta}{4} \int_{\bar{\zeta}^{*}}^{\zeta^{* j}} F(x) d x .
$$

Substituting (9.15) into (9.14), we obtain that, in any symmetric equilibrium, the expected payment of type $\zeta^{* j} \in\left[\zeta_{H}^{*}, 2\right]$ must be

$$
F\left(\zeta^{* j}\right) b\left(\zeta^{* j}\right)=F\left(\zeta^{* j}\right)\left[\omega\left(\zeta^{* j}\right)-\lambda\left(\zeta^{* j}\right)\right]-\frac{\Delta}{4} \int_{\bar{\zeta}^{*}}^{\zeta^{* j}} F(x) d x
$$

Solving (9.16) for $b\left(\zeta^{* j}\right)$ then completes the proof. Q.E.D.

Proof of Proposition 4.2: Consider the bidding function defined in Proposition 4.1. Without loss of generality, suppose that $b\left(\widetilde{\zeta}^{*}\right)=b_{o}$. We show that no type can gain from a deviation. Consider any type $\zeta^{* j}$. If this type were to select $N$, then it would receive payoff $F\left(\widetilde{\zeta}^{*}\right) \eta\left(\zeta^{* j}\right)+\left(1-F\left(\widetilde{\zeta}^{*}\right)\right) \lambda\left(\zeta^{* j}\right)$. If instead it were to select $b_{o}$, then it would receive payoff

$$
F\left(\widetilde{\zeta}^{*}\right)\left(\omega\left(\zeta^{* j}\right)-b_{o}\right)+\frac{F\left(\bar{\zeta}^{*}\right)-F\left(\widetilde{\zeta}^{*}\right)}{2}\left(\omega\left(\zeta^{* j}\right)-b_{o}+\lambda\left(\zeta^{* j}\right)\right)+\left(1-F\left(\bar{\zeta}^{*}\right)\right) \lambda\left(\zeta^{* j}\right) .
$$

Let $G_{n}\left(\zeta^{* j}\right)$ represent the the gain to type $\zeta^{* j}$ from choosing $N$ rather than $b_{o}$. Using (4.3), note that $G_{n}\left(\widetilde{\zeta}^{*}\right)=0$. Calculations give

$$
G_{n}^{\prime}\left(\zeta^{* j}\right)=\left(F\left(\bar{\zeta}^{*}\right)-F\left(\widetilde{\zeta}^{*}\right)\right) \frac{\lambda^{\prime}\left(\zeta^{* j}\right)-\omega^{\prime}\left(\zeta^{* j}\right)}{2}-F\left(\widetilde{\zeta}^{*}\right)\left(\omega^{\prime}\left(\zeta^{* j}\right)-\eta^{\prime}\left(\zeta^{* j}\right)\right)<0 .
$$

Thus, if $\zeta^{* j} \in\left[1, \widetilde{\zeta}^{*}\right)$, then type $\zeta^{* j}$ indeed prefers $N$ to $b_{o}$. Similarly, if $\zeta^{* j} \in\left(\widetilde{\zeta}^{*}, 2\right]$, then it prefers $b_{o}$ to $N$.

Next, consider any $\zeta_{S}^{* j}$ and $\zeta_{B}^{* j}$ drawn from the interval $\left[\bar{\zeta}^{*}, 2\right]$ with $\zeta_{S}^{* j}<\zeta_{B}^{* j}$. Referring to (4.4), (4.6) and (4.5), we may confirm that type $\zeta_{B}^{* j}$ loses by deviating and selecting type $\zeta_{S}^{* j \prime} s$ bid: $U\left(\zeta_{B}^{* j}, \zeta_{B}^{* j}\right)-U\left(\zeta_{S}^{* j}, \zeta_{B}^{* j}\right)$

$$
=\int_{\zeta_{S}^{* j}}^{\zeta_{B}^{* j}} U_{1}\left(x, \zeta_{B}^{* j}\right) d x=\int_{\zeta_{S}^{* j}}^{\zeta_{B}^{* j}} U_{1}\left(x, \zeta_{B}^{* j}\right)-U_{1}(x, x) d x=\int_{\zeta_{S}^{* j}}^{\zeta_{B}^{* j}} \int_{x}^{\zeta_{B}^{* j}} U_{12}(x, y) d y d x>0 .
$$


Likewise, we may verify that type $\zeta_{S}^{* j}$ loses by deviating and selecting type $\zeta_{B}^{* j \prime} s$ bid. In short, over the region for which the bid function is strictly increasing, the single-crossing property holds, and so the necessary local incentive constraint implies as well that the global incentive constraint (over the region) holds.

With these relationships in place, we show that no type can gain from a deviation. First, fix $\zeta^{* j} \in\left[1, \widetilde{\zeta}^{*}\right)$. As established above, any such type prefers $N$ to $b_{o}$, and it would thus lose by mimicking the bid of any type in the interval $\left[\widetilde{\zeta}^{*}, \bar{\zeta}^{*}\right]$. It remains to show that $\zeta^{* j}$ would lose by mimicking the bid of any type in the interval $\left[\bar{\zeta}^{*}, 2\right]$. Let $\widehat{\zeta}^{* j} \in\left[\bar{\zeta}^{*}, 2\right]$. Using (4.4), (4.6) and (4.5), observe that

$$
U_{1}\left(\widehat{\zeta}^{* j}, \zeta^{* j}\right)=U_{1}\left(\widehat{\zeta}^{* j}, \zeta^{* j}\right)-U_{1}\left(\widehat{\zeta}^{* j}, \widehat{\zeta}^{* j}\right)=-\int_{\zeta^{* j}}^{\widehat{\zeta}^{* j}} U_{12}\left(\widehat{\zeta}^{* j}, x\right) d x<0,
$$

and so type $\zeta^{* j}$ is most tempted to mimic the bid of type $\bar{\zeta}^{*}$. But this type bids $b_{o}$, and we know type $\zeta^{* j}$ prefers $N$ to $b_{o}$.

Second, fix $\zeta^{* j} \in\left[\widetilde{\zeta}^{*}, \bar{\zeta}^{*}\right]$. As established above, $\zeta^{* j} \in\left(\widetilde{\zeta}^{*}, \bar{\zeta}^{*}\right]$ prefers $b_{o}$ to $N$, while type $\widetilde{\zeta}^{*}$ is indifferent. Thus, a type $\zeta^{* j} \in\left[\widetilde{\zeta}^{*}, \widetilde{\zeta}^{*}\right]$ does not gain from mimicking a type in the interval $\left[1, \widetilde{\zeta}^{*}\right)$. It remains to show that $\zeta^{* j}$ would not gain by mimicking the bid of any type in the interval $\left[\bar{\zeta}^{*}, 2\right]$. Arguing as in the previous paragraph, it is straightforward to see that $\zeta^{* j}$ is most tempted to mimic $\bar{\zeta}^{*}$. But this type bids $b_{o}$, just as does $\zeta^{* j}$, and so $\zeta^{* j}$ does not gain from mimicking the bid of any type in $\left[\bar{\zeta}^{*}, 2\right]$.

Third, fix $\zeta^{* j} \in\left[\bar{\zeta}^{*}, 2\right]$. As established above, a global incentive constraint is satisfied over this region, and so $\zeta^{* j}$ loses by mimicking the bid of any other type in $\left[\bar{\zeta}^{*}, 2\right]$. In particular, $\zeta^{* j}>\bar{\zeta}^{*}$ loses by deviating to $b\left(\bar{\zeta}^{*}\right)=b_{o}$. It remains to show that $\zeta^{* j} \in\left[\bar{\zeta}^{*}, 2\right]$ would not gain by mimicking a type in the interval $\left[1, \widetilde{\zeta}^{*}\right)$ and selecting $N$. By $(9.17)$, type $\zeta^{* j} \in\left[\bar{\zeta}^{*}, 2\right]$ prefers $b_{o}$ to $N$. Since $\zeta^{* j}>\bar{\zeta}^{*}$ prefers its own bid to $b_{o}$, every type $\zeta^{* j} \in\left[\bar{\zeta}^{*}, 2\right]$ loses by selecting $N$.

Finally, our proof relies on the function $U$, which presumes that $b$ is strictly increasing for $\zeta^{* j}>\bar{\zeta}^{*}$. To confirm this property, we differentiate the bid function specified in Proposition 4.1 and find that $b^{\prime}\left(\zeta^{* j}\right)>0\left(b^{\prime}\left(\zeta^{* j}\right)=0\right)$ for $\zeta^{* j}>\bar{\zeta}^{*}$ $\left(\zeta^{* j}=\bar{\zeta}^{*}\right)$. Q.E.D.

Proof of Lemma 4.10: To begin, we compute the ex ante expected payment by an individual foreign country, $P\left(b_{o}\right)$. Using (9.16), this is given as

$$
P\left(b_{o}\right)=
$$




$$
\begin{aligned}
& \int_{\widetilde{\zeta}^{*}}^{\bar{\zeta}^{*}} b_{o}\left[\frac{F\left(\bar{\zeta}^{*}\right)-F\left(\widetilde{\zeta}^{*}\right)}{2}+F\left(\widetilde{\zeta}^{*}\right)\right] d F\left(\zeta^{* j}\right)+\int_{\bar{\zeta}^{*}}^{2} F\left(\zeta^{* j}\right) b\left(\zeta^{* j}\right) d F\left(\zeta^{* j}\right)= \\
& b_{o} \frac{\left[F\left(\bar{\zeta}^{*}\right)+F\left(\widetilde{\zeta}^{*}\right)\right]\left[F\left(\bar{\zeta}^{*}\right)-F\left(\widetilde{\zeta}^{*}\right)\right]}{2}+\int_{\bar{\zeta}^{*}}^{2}\left\{F\left(\zeta^{* j}\right)\left[\omega\left(\zeta^{* j}\right)-\lambda\left(\zeta^{* j}\right)\right]-\frac{\Delta}{4} \int_{\widetilde{\zeta}^{*}}^{\zeta^{* j}} F(x) d x\right\} d F\left(\zeta^{* j}\right) .
\end{aligned}
$$

Integrating by parts, we find that

$$
\int_{\bar{\zeta}^{*}}^{2} \int_{\bar{\zeta}^{*}}^{\zeta^{* j}} F(x) d x d F\left(\zeta^{* j}\right)=\int_{\bar{\zeta}^{*}}^{2} F(x)(1-F(x)) d x .
$$

Using (9.19) and simplifying, we may rewrite (9.18) as

$$
\begin{aligned}
P\left(b_{o}\right)= & b_{o} \frac{\left[F^{2}\left(\bar{\zeta}^{*}\right)-F^{2}\left(\widetilde{\zeta}^{*}\right)\right]}{2} \\
& +\int_{\widetilde{\zeta}^{*}}^{2} F\left(\zeta^{* j}\right)\left\{\left[\omega\left(\zeta^{* j}\right)-\lambda\left(\zeta^{* j}\right)\right] F^{\prime}\left(\zeta^{* j}\right)-\frac{\Delta}{4}\left(1-F\left(\zeta^{* j}\right)\right)\right\} d \zeta^{* j} .
\end{aligned}
$$

Given (9.20), since the bidders use symmetric bidding strategies, the lemma is now proved. Q.E.D.

Proof of Proposition 4.3: Recalling that $\bar{\zeta}^{*}$ and $\widetilde{\zeta}^{*}$ depend upon $b_{o}$, we use (4.1) and (4.2) to derive that

$$
\begin{aligned}
\frac{d 2 P\left(b_{o}\right)}{d b_{o}} & \mid \quad b_{o}=0=\left\{F^{2}\left(\bar{\zeta}^{*}\right)-F^{2}\left(\widetilde{\zeta}^{*}\right)+\left.2 F\left(\bar{\zeta}^{*}\right)\left(1-F\left(\bar{\zeta}^{*}\right)\right\}\right|_{b_{o}=0}\right. \\
> & \left\{F^{2}\left(\bar{\zeta}^{*}\right)-F^{2}\left(\bar{\zeta}^{*}\right)+\left.2 F\left(\bar{\zeta}^{*}\right)\left(1-F\left(\bar{\zeta}^{*}\right)\right\}\right|_{b_{o}=0}\right. \\
= & 2\left\{\left.F\left(\bar{\zeta}^{*}\right)\left(1-F\left(\bar{\zeta}^{*}\right)\right\}\right|_{b_{o}=0}>0,\right.
\end{aligned}
$$

where the first inequality uses $\widetilde{\zeta}^{*}>\widetilde{\zeta}^{*}$ and the second inequality uses $\bar{\zeta}^{*} \in(1,2)$ at $b_{o}=0$. Q.E.D. 
Proof of Lemma 6.3: We consider here whether an equilibrium can be constructed in which Home always wins and foreign countries do not use dominated strategies. To this end, we begin with the following specification:

$$
\begin{aligned}
b_{H} & =\omega(2)-\eta(2) \\
b\left(\zeta^{* j}\right) & =\max \left\{\omega\left(\zeta^{* j}\right)-\eta\left(\zeta^{* j}\right), b_{o}\right\}, \text { for all } \zeta^{* j} \in[1,2] .
\end{aligned}
$$

We consider whether Home would gain from deviating to a lower bid, $b_{H}-\epsilon$.

For $\epsilon$ positive and small, we may define the critical type $\zeta_{\epsilon}^{*}$ at which the deviant Home bid equals the foreign bid by ${ }^{20}$

$$
\omega\left(\zeta^{* j}\right)-\eta\left(\zeta^{* j}\right)=b_{H}-\epsilon .
$$

Using (9.22), we now observe that

$$
\frac{\partial \zeta_{\epsilon}^{*}}{\partial \epsilon}=-\frac{1}{\omega^{\prime}\left(\zeta_{\epsilon}^{*}\right)-\eta^{\prime}\left(\zeta_{\epsilon}^{*}\right)}=-\frac{8}{\Delta} .
$$

Thus, the payoff to Home from the deviation is

$$
\Psi(\epsilon) \equiv F^{2}\left(\zeta_{\epsilon}^{*}\right)\left[W_{N R}-\left(b_{H}-\epsilon\right)\right]+\left[1-F^{2}\left(\zeta_{\epsilon}^{*}\right)\right] W_{R} .
$$

Home will thus deviate if $\Psi(\epsilon)>\Psi(0)$ for some small $\epsilon$.

To explore this possibility, we use (9.24) to compute

$$
\Psi^{\prime}(\epsilon)=2 F\left(\zeta_{\epsilon}^{*}\right) F^{\prime}\left(\zeta_{\epsilon}^{*}\right) \frac{\partial \zeta_{\epsilon}^{*}}{\partial \epsilon}\left[W_{N R}-\left(b_{H}-\epsilon\right)-W_{R}\right]+F^{2}\left(\zeta_{\epsilon}^{*}\right) .
$$

Using (9.23) and (9.21), we may rewrite (9.25) as

$$
\Psi^{\prime}(\epsilon)=-2 F\left(\zeta_{\epsilon}^{*}\right) F^{\prime}\left(\zeta_{\epsilon}^{*}\right) \frac{8}{\Delta}\left[W_{N R}-W_{R}-(\omega(2)-\eta(2))+\epsilon\right]+F^{2}\left(\zeta_{\epsilon}^{*}\right) .
$$

Now, when $\epsilon=0$, we have that $\zeta_{\epsilon}^{*}=2$, and we may derive from (9.26) that

$$
\begin{aligned}
\Psi^{\prime}(0) & \left.=-4 F^{\prime}(2)\left[\zeta^{H}-1+\frac{1}{2}\left[4 \tau_{o}+3 \Delta\right]\right)\right]+1 \\
& >-4 F^{\prime}(2)\left[\zeta^{H}-\frac{2}{3}\right]+1 \geq-F^{\prime}(2)\left[\frac{16}{3}\right]+1,
\end{aligned}
$$

\footnotetext{
${ }^{20}$ Under A4, we know that $\omega(2)-\lambda(2)>b_{o}$, from which it follows that $\omega(2)-\eta(2)>b_{o}$. For $\epsilon$ small, it thus follows that $b\left(\zeta_{\epsilon}^{*}\right)>b_{o}$. If we assume further that $\omega(1)-\eta(1)>b_{o}$, then the definition of $\zeta_{\epsilon}^{*}$ is appropriate even for larger values of $\epsilon$.
} 
where the first inequality uses A3 and the second inequality uses A2 $\left(\zeta^{H} \leq 2\right)$. Using (9.27), it thus follows that, when $F^{\prime}(2)<3 / 16$, the specification in $(9.21)$ cannot constitute a symmetric equilibrium, since Home would enjoy a strict gain $\left(\Psi^{\prime}(0)>0\right)$ if it were to slightly reduce its bid from $b_{H}$.

Building on this derivation, we now establish the lemma. Suppose to the contrary that a symmetric equilibrium exists in which Home always wins and foreign countries do not use dominated strategies, when $F^{\prime}(2)<3 / 16$. From Lemma 6.2, we know that $b_{H} \in\left[\omega(2)-\eta(2), \zeta^{H} \frac{\Delta}{4}\right]$. Furthermore, as argued in the text, for a foreign country of type $\zeta^{* j}$, any bid $b$ such that $b>\max \left\{\omega\left(\zeta^{* j}\right)-\right.$ $\left.\eta\left(\zeta^{* j}\right), b_{o}\right\}$ is dominated by the alternative strategy of selecting $N$. By A3, $\omega(2)-$ $\eta(2)>\omega(2)-\lambda(2)>b_{o}$. Thus, if foreign countries do not use dominated strategies, then $b\left(\zeta^{* j}\right) \leq \omega(2)-\eta(2)$. It follows that Home would never bid $b_{H}>\omega(2)-\eta(2)$, since Home could continue winning with a slightly lower bid. We thus conclude that, if a symmetric equilibrium exists in which Home wins and foreign countries do not use dominated strategies, then Home must bid $b_{H}=\omega(2)-\eta(2)$ and the foreign country bids must satisfy $b \leq \max \left\{\omega\left(\zeta^{* j}\right)-\eta\left(\zeta^{* j}\right), b_{o}\right\}$. Now, if Home bids $b_{H}=\omega(2)-\eta(2)$, then Home is least tempted to deviate with a slightly lower bid, if foreign bids are as high as possible while respecting the requirement that dominated strategies not be used. For the higher foreign types, this means that $b\left(\zeta^{* j}\right)=\max \left\{\omega\left(\zeta^{* j}\right)-\eta\left(\zeta^{* j}\right), b_{o}\right\}$. But this is the specification given above in (9.21), and we establish in (9.27) that Home would then deviate to a slightly lower bid if $F^{\prime}(2)<3 / 16$. Q.E.D.

Proof of Lemma 6.4: With $b_{o}$ sufficiently close to zero, we know from Lemma 6.1 that Home does not select $b_{H}=N$. Thus, it is not possible that Home sometimes wins, by not bidding and escaping retaliation sometimes when auction failures occur. At the other extreme, if $b_{H} \geq \omega(2)-\eta(2)$, then Home must always win. Therefore, if Home wins sometimes, then it must be that $b_{H} \in\left[b_{o}, \omega(2)-\eta(2)\right)$. Hence, we assume that a symmetric equilibrium exists in which Home sometimes wins with $b_{H} \in\left[b_{o}, \omega(2)-\eta(2)\right)$. We seek a contradiction.

Suppose that the foreign countries have a pooling region on which they always or sometimes win. Formally, suppose that there exists $\left[\zeta_{1}^{* j}, \zeta_{2}^{* j}\right]$ such that $\zeta_{1}^{* j}<\zeta_{2}^{* j}$ and $b\left(\zeta^{* j}\right)=\bar{b} \geq b_{H}$ for all $\zeta^{* j} \in\left[\zeta_{1}^{* j}, \zeta_{2}^{* j}\right]$, where Home does not always win a tie (when $\bar{b}=b_{H}$ ). If $\bar{b}=b_{H}$, then Home could raise its bid by $\epsilon$ and gain, since by (5.4) we know that $W_{N R}-W_{R}>\omega(2)-\lambda(2)>b_{H}$. If $\bar{b}>b_{H}$, then $\bar{b}>b_{o}$. As in the proof of Claim 1 in Lemma 4.4, either type $\zeta_{1}^{* j}$ will gain from a lower bid or type $\zeta_{2}^{* j}$ will gain from a higher bid. (The arguments are unaffected by $b_{H}$, since 
$b_{H}$ is lower in this case than the relevant bids.) Thus, it is impossible that the foreign countries have a pooling region on which they always or sometimes win. In sum, if foreign countries use a pooling region, then on that region they must always lose: either $\bar{b}<b_{H}$, or $\bar{b}=b_{H}$ and Home always wins the tie. ${ }^{21}$

Given our assumption that Home sometimes wins, it is necessary that there exists a positive measure of foreign types that win against Home. As just established, these types cannot pool anywhere, and so there must exist a positive measure of foreign types whose bids exceed $b_{H}$. Let $\zeta_{B}^{* j}$ and $\zeta_{S}^{* j}$ be two such types, with $\zeta_{B}^{* j}>\zeta_{S}^{* j}$. Arguing as in Lemma 4.1, with the definition of $\mathbf{B}$ modified so that $\mathbf{B} \equiv \operatorname{prob}\left\{b\left(\zeta^{* j}\right)>b_{H}\right\}$, we may derive that all types in the interval $\left[\zeta_{S}^{* j}, \zeta_{B}^{* j}\right]$ bid above $b_{H}$ and further that $b\left(\zeta_{B}^{* j}\right) \geq b\left(\zeta_{S}^{* j}\right)$. Since pooling regions are not possible for bids that exceed $b_{H}$, we know that $b\left(\zeta_{B}^{* j}\right)>b\left(\zeta_{S}^{* j}\right)$. It follows that there must exist $\widehat{\zeta}^{*} \in(1,2)$ such that, for all $\zeta^{* j}>\widehat{\zeta}^{*}, b\left(\zeta^{* j}\right)>b_{H}$ and $b$ is strictly increasing. Furthermore, if we let $\widehat{\zeta}^{*}$ denote the lowest such value, then we know as well that $b\left(\widehat{\zeta}^{*}\right)=b_{H}$. Otherwise, there would be a gap between $b\left(\widehat{\zeta}^{*}\right)$ and $b_{H}$, and in analogy with Lemma 4.5 this would give types near $\widehat{\zeta}^{*}$ a strict benefit from deviating to a lower bid that rests in that gap.

Therefore, we consider now the possibility that Home sometimes wins and there exists $\widehat{\zeta}^{*} \in(1,2)$ such that $b\left(\widehat{\zeta}^{*}\right)=b_{H}$ and, for all $\zeta^{* j}>\widehat{\zeta}^{*}, b\left(\zeta^{* j}\right)>b_{H}$ and $b$ is strictly increasing. We propose to exploit the following tension. Looking toward lower types, type $\widetilde{\zeta}^{*}$ (perhaps plus $\epsilon$ ) must be indifferent between beating Home and not, indicating a relationship between $\omega\left(\widehat{\zeta}^{*}\right)$ and $\eta\left(\widehat{\zeta}^{*}\right)$. Looking toward higher types, type $\widehat{\zeta}^{*}$ (perhaps plus $\epsilon$ ) must be indifferent between bidding its equilibrium bid and that assigned to a slightly higher type, indicating a relationship between $\omega\left(\widehat{\zeta}^{*}\right)$ and $\lambda\left(\widehat{\zeta}^{*}\right)$. In our basic auction, as Lemmas 4.4 and 4.9 indicate, this tension is resolved with a pooling region at $b_{o}$. But in the extended auction, as just discussed, we cannot have a pooling region over which foreign countries sometimes or always win. This suggests that a contradiction is inevitable.

To confirm this suggestion, we proceed as follows. We note first that type $\widehat{\zeta}^{*}$ (perhaps plus $\epsilon$ ) must be indifferent between beating Home with a bid at (or just above) $b_{H}$ and losing to Home: $F\left(\widehat{\zeta}^{*}\right)\left[\omega\left(\widehat{\zeta}^{*}\right)-b\left(\widehat{\zeta}^{*}\right)\right]+\left[1-F\left(\widehat{\zeta}^{*}\right)\right] \lambda\left(\widehat{\zeta}^{*}\right)=$ $F\left(\widehat{\zeta}^{*}\right) \eta\left(\widehat{\zeta}^{*}\right)+\left[1-F\left(\widehat{\zeta}^{*}\right)\right] \lambda\left(\widehat{\zeta}^{*}\right)$. We thus conclude that

$$
\omega\left(\widehat{\zeta}^{*}\right)-b\left(\widehat{\zeta}^{*}\right)=\eta\left(\widehat{\zeta}^{*}\right) .
$$

\footnotetext{
${ }^{21}$ This is consistent with the equilibrium in Lemma 6.2, in which Home always wins.
} 
This is the relationship between $\omega\left(\widehat{\zeta}^{*}\right)$ and $\eta\left(\widehat{\zeta}^{*}\right)$.

We note second that any type at or above $\widehat{\zeta}^{*}$ must satisfy a local incentive compatibility condition, ensuring that no gain is possible by mimicking the behavior of a slightly higher type. Using (4.4) and (4.6), we may again derive (9.12), which now must hold for all $\zeta^{* j} \in\left[\widehat{\zeta}^{*}, 2\right]$. Taking (9.12) and integrating over the range $\left[\widehat{\zeta}^{*}, \zeta^{* j}\right]$, we derive an expression analogous to $(9.13)$. In particular, we find that the expected payment of type $\zeta^{* j} \geq \widehat{\zeta}^{*}$ is

$$
F\left(\zeta^{* j}\right) b\left(\zeta^{* j}\right)=F\left(\widehat{\zeta}^{*}\right) b\left(\widehat{\zeta}^{*}\right)+\int_{\widehat{\zeta}^{*}}^{\zeta^{* j}} F^{\prime}(x)[\omega(x)-\lambda(x)] d x .
$$

Integrating by parts, we see that

$$
\begin{gathered}
\int_{\widehat{\zeta}^{*}}^{\zeta^{* j}} F^{\prime}(x)[\omega(x)-\lambda(x)] d x= \\
F\left(\zeta^{* j}\right)\left[\omega\left(\zeta^{* j}\right)-\lambda\left(\zeta^{* j}\right)\right]-F\left(\widehat{\zeta}^{*}\right)\left[\omega\left(\widehat{\zeta}^{*}\right)-\lambda\left(\widehat{\zeta}^{*}\right)\right]-\int_{\widehat{\zeta}^{*}}^{\zeta^{* j}} F(x)\left[\omega^{\prime}(x)-\lambda^{\prime}(x)\right] d x .
\end{gathered}
$$

Substituting (9.30) into (9.29), we obtain

$$
\begin{gathered}
F\left(\zeta^{* j}\right) b\left(\zeta^{* j}\right)= \\
F\left(\widehat{\zeta}^{*}\right) b\left(\widehat{\zeta}^{*}\right)-F\left(\widehat{\zeta}^{*}\right)\left[\omega\left(\widehat{\zeta}^{*}\right)-\lambda\left(\widehat{\zeta}^{*}\right)\right]+F\left(\zeta^{* j}\right)\left[\omega\left(\zeta^{* j}\right)-\lambda\left(\zeta^{* j}\right)\right]-\int_{\widehat{\zeta}^{*}}^{\zeta^{* j}} F(x)\left[\omega^{\prime}(x)-\lambda^{\prime}(x)\right] d x .
\end{gathered}
$$

Solving (9.31) for $b\left(\zeta^{* j}\right)$ we obtain

$$
b\left(\zeta^{* j}\right)=
$$


$\frac{F\left(\widehat{\zeta}^{*}\right)}{F\left(\zeta^{* j}\right)} b\left(\widehat{\zeta}^{*}\right)-\frac{F\left(\widehat{\zeta}^{*}\right)}{F\left(\zeta^{* j}\right)}\left[\omega\left(\widehat{\zeta}^{*}\right)-\lambda\left(\widehat{\zeta}^{*}\right)\right]+\left[\omega\left(\zeta^{* j}\right)-\lambda\left(\zeta^{* j}\right)\right]-\frac{1}{F\left(\zeta^{* j}\right)} \int_{\widetilde{\zeta}^{*}}^{\zeta^{* j}} F(x)\left[\omega^{\prime}(x)-\lambda^{\prime}(x)\right] d x$

This equation indicates a relationship between $\omega\left(\widehat{\zeta}^{*}\right)$ and $\lambda\left(\widehat{\zeta}^{*}\right)$.

We next differentiate the bidding function in (9.32). We find that

$$
\begin{gathered}
b^{\prime}\left(\zeta^{* j}\right)= \\
\frac{F^{\prime}\left(\zeta^{* j}\right)}{\left(F\left(\zeta^{* j}\right)\right)^{2}}\left\{-F\left(\widehat{\zeta}^{*}\right) b\left(\widehat{\zeta}^{*}\right)+F\left(\widehat{\zeta}^{*}\right)\left[\omega\left(\widehat{\zeta}^{*}\right)-\lambda\left(\widehat{\zeta}^{*}\right)\right]+\int_{\widehat{\zeta}^{*}}^{\zeta^{* j}} F(x)\left[\omega^{\prime}(x)-\lambda^{\prime}(x)\right] d x\right\} .
\end{gathered}
$$

Notice that, if

$$
\omega\left(\widehat{\zeta}^{*}\right)-b\left(\widehat{\zeta}^{*}\right)=\lambda\left(\widehat{\zeta}^{*}\right)
$$

so that type $\widehat{\zeta}^{*}$ were indifferent between trading (locally) winning and losing events, as was true in our equilibrium for $\bar{\zeta}^{*}$ in the basic auction, then the first two terms in (9.33) would cancel, and it would follow directly from (9.33) that $b^{\prime} \geq 0$. But (9.34) does not hold here; rather, we have that $b\left(\widehat{\zeta}^{*}\right)$ satisfies (9.28). Imposing (9.28), we use (9.33) to write

$$
\begin{gathered}
b^{\prime}\left(\zeta^{* j}\right)= \\
\frac{F^{\prime}\left(\zeta^{* j}\right)}{\left(F\left(\zeta^{* j}\right)\right)^{2}}\left\{F\left(\widehat{\zeta}^{*}\right)\left[\eta\left(\widehat{\zeta}^{*}\right)-\lambda\left(\widehat{\zeta}^{*}\right)\right]+\int_{\widehat{\zeta}^{*}}^{\zeta^{* j}} F(x)\left[\omega^{\prime}(x)-\lambda^{\prime}(x)\right] d x\right\} .
\end{gathered}
$$

But using (9.35), we see that

$$
b^{\prime}\left(\widehat{\zeta}^{*}\right)=\frac{F^{\prime}\left(\widehat{\zeta}^{*}\right)}{F\left(\widehat{\zeta}^{*}\right)}\left[\eta\left(\widehat{\zeta}^{*}\right)-\lambda\left(\widehat{\zeta}^{*}\right)\right]<0
$$


But (9.36) contradicts the possibility assumed above that $b\left(\widehat{\zeta}^{*}\right)=b_{H}$ and, for all $\zeta^{* j}>\widehat{\zeta}^{*}, b\left(\zeta^{* j}\right)>b_{H}$ and $b$ is strictly increasing. Q.E.D.

Proof of Lemma 7.1: To show that $W_{N R}-2 P\left(b_{o}\right)>F^{2}\left(\widetilde{\zeta}^{*}\right) W_{N R}+\left[1-F^{2}\left(\widetilde{\zeta}^{*}\right)\right] W_{R}$ for any $\zeta^{H} \geq 1$, we first rewrite this inequality as

$\left[1-F^{2}\left(\widetilde{\zeta}^{*}\right)\right] \frac{\Delta}{4} \zeta^{H}>b_{o}\left[F^{2}\left(\bar{\zeta}^{*}\right)-F^{2}\left(\widetilde{\zeta}^{*}\right)\right]+2 \int_{\bar{\zeta}^{*}}^{2} F(\zeta)\left\{[\omega(\zeta)-\lambda(\zeta)] F^{\prime}(\zeta)-\frac{\Delta}{4}(1-F(\zeta))\right\} d \zeta$

If this inequality holds for any $\bar{\zeta}^{*}$ and $\widetilde{\zeta}^{*}$ consistent with $\mathrm{A} 4$ when $\zeta^{H}$ is set to one and $b_{o}$ is set to its maximal permissible level under A4 (i.e., $\omega(2)-\lambda(2)$ ), then it must hold for $\zeta^{H} \geq 1$ for any $b_{o}$ satisfying A4. Hence, setting $\zeta^{H}$ to one and setting $b_{o} \equiv \omega(2)-\lambda(2)=\frac{\Delta}{4}\left(1-\left(4 \tau_{o}+2 \Delta\right)\right)$, the above inequality can be written, after some manipulation, as

$$
\int_{\bar{\zeta}^{*}}^{2} F(\zeta) F^{\prime}(\zeta)[2-\zeta] d \zeta+\left[1-F^{2}(\widetilde{\zeta})\right]\left(2 \tau_{o}+\Delta\right)>0>-\int_{\bar{\zeta}^{*}}^{2} F(\zeta)[1-F(\zeta)] d \zeta
$$

Therefore, $W_{N R}-2 P\left(b_{o}\right)>F^{2}\left(\widetilde{\zeta}^{*}\right) W_{N R}+\left[1-F^{2}\left(\widetilde{\zeta}^{*}\right)\right] W_{R}$ for any $\zeta^{H} \geq 1$. Q.E.D.

\section{References}

Bagwell, K. and R. W. Staiger (1990), "A Theory of Managed Trade," American Economic Review, 80, 779-95.

Bagwell, K. and R. W. Staiger (1997), "Multilateral Tariff Cooperation During the Formation of Customs Unions," Journal of International Economics, 42, 91-123.

Bagwell, K. and R. W. Staiger (1999), "An Economic Theory of GATT," American Economic Review, 89, 215-48.

Bagwell, K. and R. W. Staiger (2001), "Reciprocity, Non-Discrimination and Preferential Agreements in the Multilateral Trading System," European Journal of Political Economy, 17, 281-325. 
Bagwell, K. and R. W. Staiger (2002), The Economics of the World Trading System, Cambridge: The MIT Press.

Baldwin, R. (1987), "Politically Realistic Objective Functions and Trade Policy," Economic Letters, 24, 287-90.

Das Varma (2002), "Standard Auctions with Idendity-Dependent Externalities," Rand Journal of Economics, 33.4, Winter, 689-704.

Dixit, A. (1987), "Strategic Aspects of Trade Policy," in T. Bewley (ed.), Advances in Economic Theory: Fifth World Congress, New York: Cambridge University Press.

Ederington, J. (2001), "International Coordination of Trade and Domestic Policies," American Economic Review, 91, 1580-93.

Ettinger, D. (2002), "Auctions and Shareholdings," mimeo, CREST-LEI and CERAS-ENPC, Paris.

Haile, P. (2000), "Partial Pooling at the Reserve Price in Auctions with Resale Opportunities," Games and Economic Behavior, 33.2, 231-48.

Jehiel, P. and B. Moldovanu (1996), "Strategic Nonparticipation," Rand Journal of Economics, 27, 84-98.

Jehiel, P. and B. Moldovanu (2000), "Auctions with Downstream Interaction Among Buyers," Rand Journal of Economics, 31.4, Winter, 768-92.

Jehiel, P. and B. Moldovanu (2001), "Efficient Design with Interdependent Valuations," Econometrica, 69.5, 1237-59.

Limao, N. (2000), "Trade Policy, Cross-Border Externalities and Lobbies: Do Linked Agreements Enforce More Cooperative Outcomes?," mimeo, University of Maryland.

Maggi, G. (1999), "The Role of Multilateral Institutions in International Trade Cooperation," American Economic Review, 89, 190-214.

Riley, J. and W. F. Samuelson (1981), "Optimal Auctions," American Economic Review, 71.3, 381-92.

WTO (2002), "Dispute Settlement Body - Special Session - Negotiations on Improvements and Clarifications of the Dispute Settlement Understanding - Proposal by Mexico," November 4, catalogue record TN/DS/W/23. 


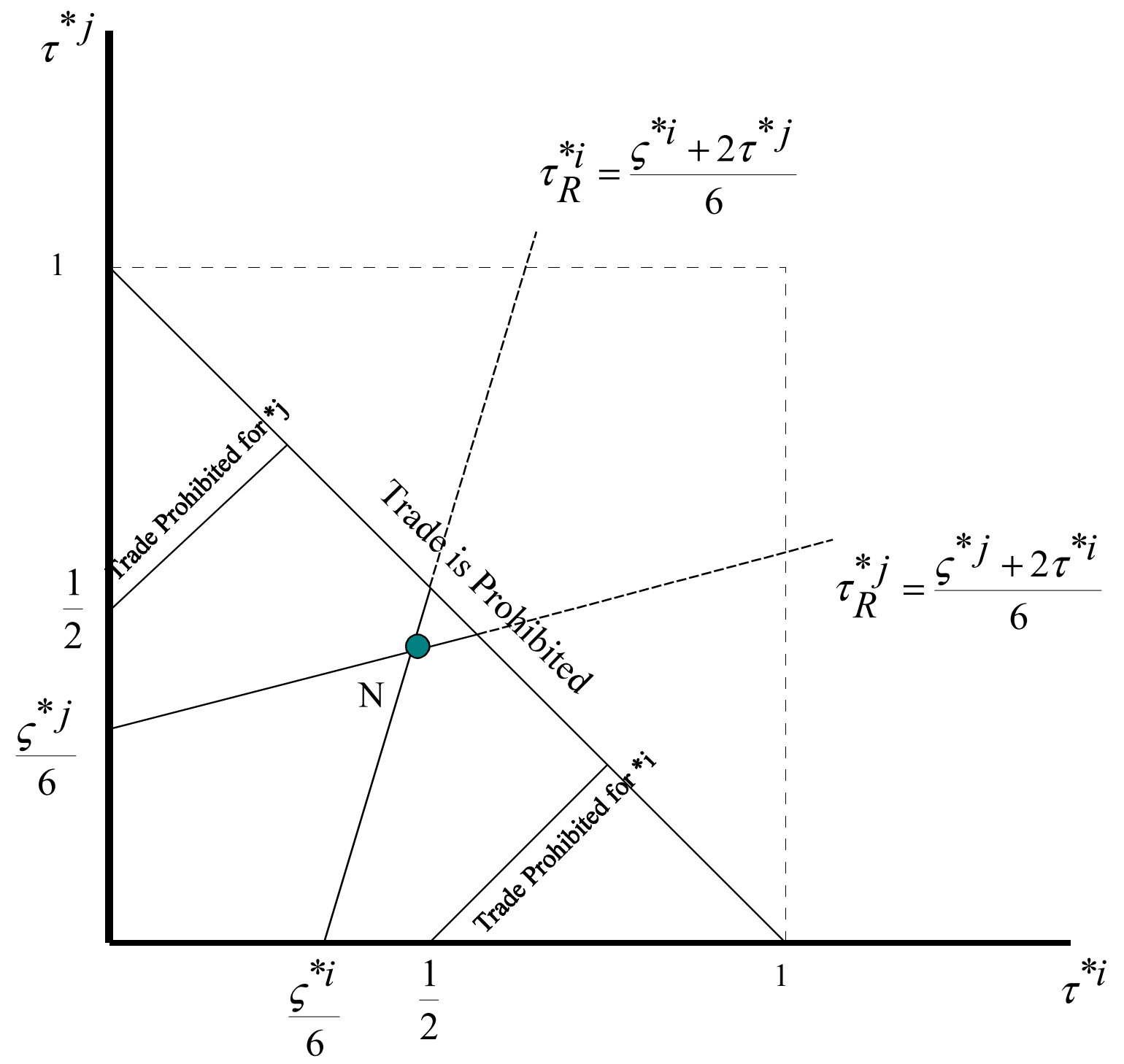

Figure 1 


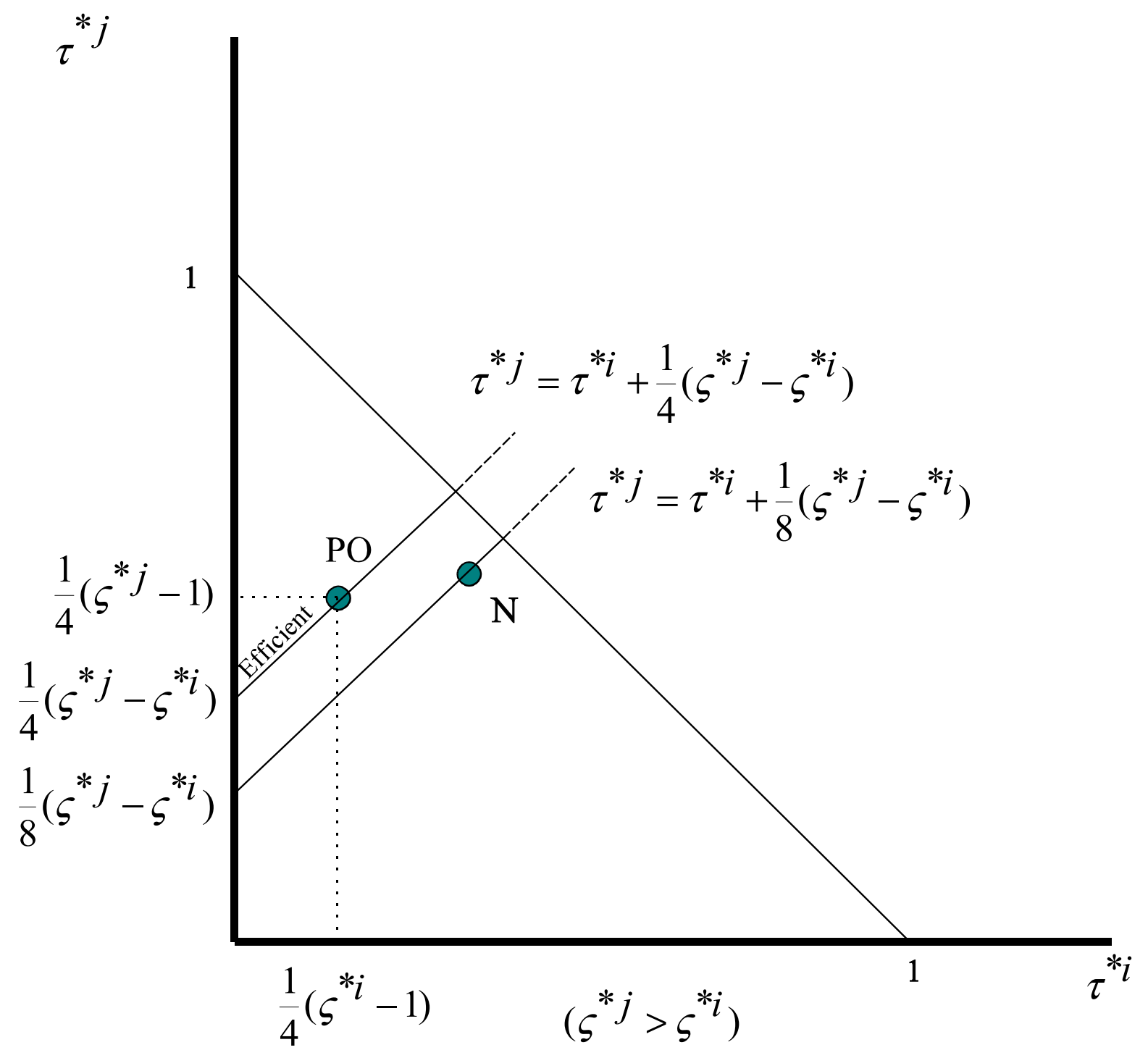

Figure 2 


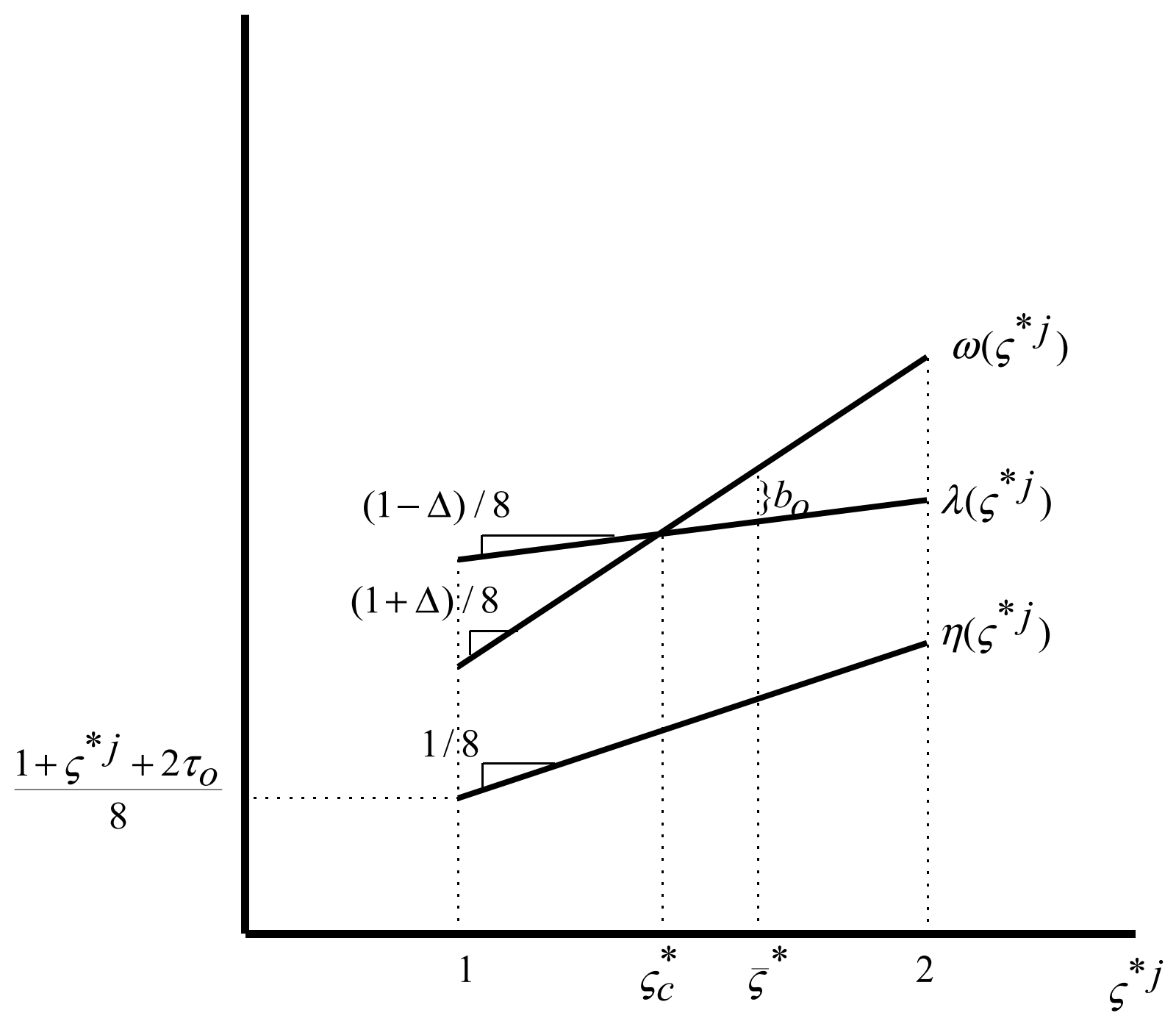

Figure 3 


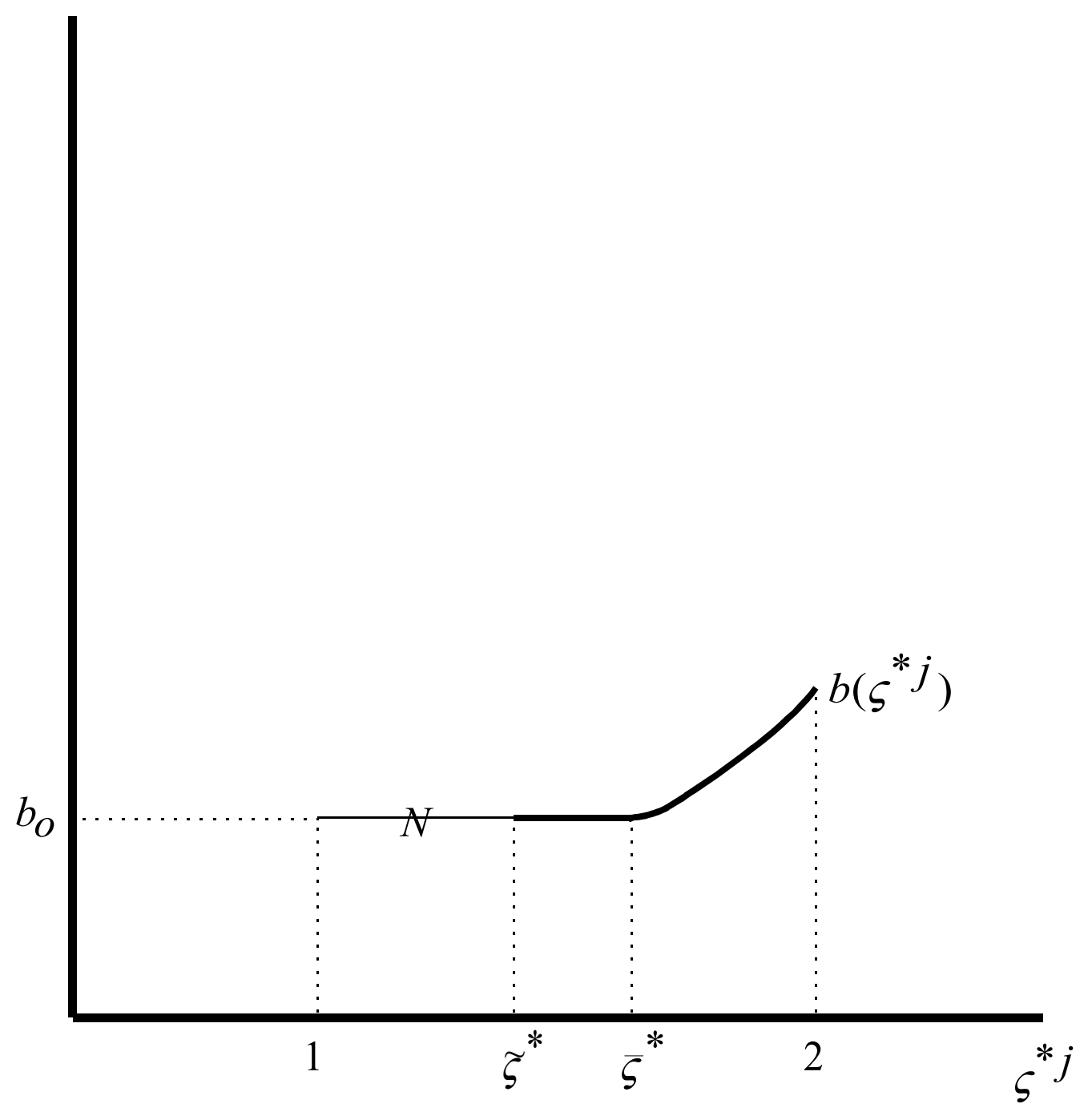

Figure 4 